Article

\title{
Overview of Void Fraction Measurement Techniques, Databases and Correlations for Two-Phase Flow in Small Diameter Channels
}

\author{
Álvaro Roberto Gardenghi, Erivelto dos Santos Filho, Daniel Gregório Chagas, \\ Guilherme Scagnolatto, Rodrigo Monteiro Oliveira and Cristiano Bigonha Tibiriçá * \\ Heat Transfer Research Group, Department of Mechanical Engineering, Sao Carlos School of Engineering, \\ University of São Paulo, Av. Trab. São Carlense, 400, São Carlos SP 13566-590, Brazil; \\ alvarogardenghi@gmail.com (Á.R.G.); erivelto.filho@usp.br (E.d.S.F.); daniel.gregorio.ch@gmail.com (D.G.C.); \\ guilherme.scagnolatto@usp.br (G.S.); rodrigo_eng.mecanico@yahoo.com.br (R.M.O.) \\ * Correspondence: bigonha@sc.usp.br
}

Received: 21 October 2020; Accepted: 17 November 2020; Published: 20 November 2020

\begin{abstract}
Void fraction is one of the most important parameters for the modeling and characterization of two-phase flows. This manuscript presents an overview of void fraction measurement techniques, experimental databases and correlations, in the context of microchannel two-phase flow applications. Void fraction measurement techniques were reviewed and the most suitable techniques for microscale measurements were identified along its main characteristics. An updated void fraction experimental database for small channel diameter was obtained including micro and macrochannel two-phase flow data points. These data have channel diameter ranging from 0.5 to $13.84 \mathrm{~mm}$, horizontal and vertical directions, and fluids such as air-water, R410a, R404a, R134a, R290, R12 and R22 for both diabatic and adiabatic conditions. New published void fraction correlations as well high cited ones were evaluated and compared to this small-diameter void fraction database in order to quantify the prediction error of them. Moreover, a new drift flux correlation for microchannels was also developed, showing that further improvement of available correlations is still possible. The new correlation was able to predict the microchannel database with mean absolute relative error of $9.8 \%$, for $6 \%$ of relative improvement compared to the second-best ranked correlation for small diameter channels.
\end{abstract}

Keywords: void fraction measurement techniques; microchannel experimental databases; correlations; hold up

\section{Introduction}

Void fraction, an important factor for the study and characterization of multiphase flows, is a dimensionless parameter defined by the ratio between the gas phase area and the total flow area in a cross-sectional evaluation. It affects flow characteristics such as heat transfer coefficient, pressure drop and flow pattern, which directly affect several applications (e.g., refrigeration and air conditioning, fluid transport through ducts, power cycles, and heat exchangers).

Research on two-phase flow void fraction started at the end of 1940s, with experimental and theoretical approaches that used macrochannels (ducts above the transition criteria [1], which in terms of channels diameter gives on average a $3 \mathrm{~mm}$ hydraulic diameter). However, the microchannel two-phase flow has been widely applied over the past two decades. One of the reasons for such an increase is new applications requiring compact heat exchangers, e.g., cooling of electric cars, compact solar power thermal systems, electronic components, turbines and new compact actuators [2]. The advantages offered by microchannel heat exchangers include more capacity to operate at high pressures, higher 
heat transfer area per volume, and higher heat transfer coefficients under same conditions. Since discrepancies have been observed in the use of conventional "macroscale" design methods under microscale conditions, research has focused on the identification of differences between microscale and macroscale flows [1,3]. Several differences have been detected in heat transfer, flow pattern and void fraction behaviors over the years, and the microchannel two-phase flow has been modeled through new correlations for those parameters. Experiments have led to the emergence of new void fraction correlations to be tested by independent investigators. In addition, experimental methods should be adapted and developed for use in small-diameter tubes, since additional measurement problems arise with very small-diameters.

Chexal et al. [4] evaluated eight well-known void fraction models using 1500 data points that covered several operation conditions such as high pressures with high and low flow rates, low pressures and low flow rates, countercurrent flooding limitations, natural circulation flows and cocurrent downflows for a steady-state steam-water flow in vertical configurations. Woldesemayat and Ghajar [5] compared 68 void fraction correlations using 2845 data points with wide operational conditions. Their study revealed many correlations are highly restricted and performed satisfactorily only in some regions of the database. Cioncolini and Thome [6] compared their proposed correlation to those of Woldesemayat and Ghajar [5], and Lockhart and Martinelli [7] using 2673 data points containing eight different combinations of gas-liquid and vapor-liquid. Xu and Fang [8] compared 41 void fraction correlations using 1574 data points with 5 different refrigerants. The hydraulic diameters ranged from 0.5 to $10 \mathrm{~mm}$, and the mass fluxes varied between 40 and $1000 \mathrm{~kg} \mathrm{~s}^{-1} \mathrm{~m}^{-2}$. The authors [8] proposed a correlation for both macro and microchannels. Jin et al. [9] compared 46 correlations under several operation conditions including four inclinations, and concluded inclination exerts no significant influence on the prediction error of a given correlation.

Considering such trends, this manuscript presents an updated study of measurement methods, databases and literature correlations for two-phase flow void fraction in small-diameter tubes (expression used in this text to refer to microchannels range in addition to the lower diameter range of macrochannels). In total, nine experimental methods were reviewed, and a wide experimental database containing 2361 points for channel diameters smaller than $13.84 \mathrm{~mm}$ was analyzed consisting of microchannels and conventional channels. A total of 20 void fraction correlations were tested including the most recent ones. A new drift flux model correlation is also proposed based on only microchannel data and its performance was compared to the complete small channel diameter database. All analyses were used for identifying new research opportunities for studies on void fractions in small-diameter channels.

\section{Void Fraction Measurement Techniques}

Over the last few decades, many measurement methods for void fraction determination in two-phase flows have been developed [10-35]. Void fraction measurements can be defined at a point (local), over a line, over a surface or over a volume. Local measurement detects the presence of a phase or not in a point at a given time. Line measurement accounts for the fraction of a line occupied by a phase at a specific time. The surface measurement accounts for the fraction of a surface occupied by a phase at a specific time. The volumetric measurement accounts for fraction of a volume occupied by a phase in an instant.

The Table 1 summarizes some studies, showing the measurement techniques, the tested fluids, the internal tube diameters and boundary conditions (adiabatic or diabatic two-phase flow). The measurement techniques can be grouped in four major principles: (i) mechanical; (ii) optical; (iii) ionizing radiation; and (iv) electrical. In the next subsections, these techniques are reviewed and analyzed in the context of two-phase flows in small-diameter channels. All techniques described in Table 1 can be adjusted to give local, line, surface or volumetric measurements. 
Table 1. Studies of two-phase flow using different methods of void fraction measurement.

\begin{tabular}{|c|c|c|c|c|c|}
\hline Principle & Technique & Authors & $\mathrm{D}[\mathrm{mm}]$ & Fluid & Type \\
\hline \multirow{11}{*}{ Mechanical } & \multirow{7}{*}{$\begin{array}{l}\text { Quick-closing } \\
\text { valves }\end{array}$} & Hashizume [10] & 10.0 & R12; R22 & Evap. \\
\hline & & Schrage et al. [11] & 7.94 & Water-air & Adiab. \\
\hline & & Xu et al. [12] & 9.79 & Water-air & Adiab. \\
\hline & & Wilson [13] & 6.12 & R134a; R410A & Evap. \\
\hline & & Yashar et al. [14] & 4.26 & R410A & Evap. \\
\hline & & Koyama et al. [15] & 7.52 & R134a & Adiab. \\
\hline & & Srisomba et al. [16] & 8.0 & R134a & Adiab. \\
\hline & \multirow{3}{*}{ Ultrasound } & Zheng and Zhang [17] & 76.0 & Water & Adiab. \\
\hline & & Murakawa et al. [18] & 50.0 & $\begin{array}{l}\text { Water (with } \\
\text { nylon)-air }\end{array}$ & Adiab. \\
\hline & & Vasconcelos et al. [19] & 54.0 & Water-air & Adiab. \\
\hline & Pressure drop & Jia et al. [20] & 50.0 & Water-air & Adiab. \\
\hline \multirow{3}{*}{ Optical } & Light & Revellin et al. [21] & 0.5 & R134a & Evap. \\
\hline & Laser & Sempértegui-Tapia et al. [22] & $1.1 ; 2.32$ & R134a; R245fa & Adiab. \\
\hline & $\begin{array}{l}\text { Particle Image } \\
\text { Velocimetry (PIV) }\end{array}$ & Harada and Murakami [23] & $\mathrm{n} / \mathrm{d}$ & He II; He I & $\mathrm{n} / \mathrm{d}$ \\
\hline \multirow{3}{*}{$\begin{array}{l}\text { Ionizing } \\
\text { radiation }\end{array}$} & $\begin{array}{l}\text { Gamma-ray } \\
\text { radiation }\end{array}$ & Dowlati et al. [24] & 12.7 & Water-air & Adiab. \\
\hline & $\mathrm{X}$-ray radiation & Kendoush and Sarkis [25] & $28.0 ; 36.0$ & Water-air & $\begin{array}{l}\text { Adiab. } \\
\text { Diab. }\end{array}$ \\
\hline & Neutron emission & Mishima and Hibiki [26] & 1.05 & Water-air & $\mathrm{n} / \mathrm{d}$ \\
\hline \multirow{9}{*}{ Electrical } & \multirow{2}{*}{$\begin{array}{l}\text { Capacitive (ring } \\
\text { sensor) } \\
\text { Impedance }\end{array}$} & Portillo et al. [27] & 3.0 & R410A & Evap. \\
\hline & & Paranjape et al. [28] & 0.78 & Water-air & Adiab. \\
\hline & $\begin{array}{l}\text { Capacitive } \\
\text { (Annular sensor) }\end{array}$ & $\begin{array}{l}\text { Shedd [29] } \\
\text { Olivier et al. [30] }\end{array}$ & $\begin{array}{l}0.508 \\
8.38\end{array}$ & $\begin{array}{l}\text { R410A } \\
\text { R134a }\end{array}$ & $\begin{array}{l}\text { Cond. } \\
\text { Cond. }\end{array}$ \\
\hline & $\begin{array}{l}\text { Capacitive } \\
\text { (concave sensor) }\end{array}$ & De Kerpel et al. [31] & 8.0 & R134a, R410A & Adiab. \\
\hline & Resistive & Barreto et al. [32] & 1.2 & Water-air & Adiab. \\
\hline & $\begin{array}{l}\text { Capacitively } \\
\text { coupled contactless } \\
\text { conductivity } \\
\text { detection }\left(C^{4} D\right)\end{array}$ & Zhou [33] & $2.8 ; 3.9$ & Water-nitrogen & Adiab. \\
\hline & $\begin{array}{l}\text { Single-wire } \\
\text { capacitance probe }\end{array}$ & Huang et al. [34] & 29 & Water-air & Adiab. \\
\hline & \multirow{2}{*}{$\begin{array}{l}\text { Multi-wire } \\
\text { capacitance probe }\end{array}$} & He et al. [35] & 50 & Water-air & Adiab. \\
\hline & & Netto and Peresson [36] & 53 & Water-air & Adiab. \\
\hline
\end{tabular}

n/d: no data.

\subsection{Quick-Closing Valves}

In this method, valves are placed at each side of the test section in which the void fraction is to be measured. After the desired flow conditions is set up, an electrical circuit acts on the rapid closing valves, trapping the flow on the test section by closing the valves V1 and V2, and opening the valves V3 and V4, allowing the fluid to flow along the bypass (see Figure 1). The valves are closed and opened simultaneously, which may result in an error in the synchronization of these valves typically less than about $20 \mathrm{~ms}$, which may result on a void fraction error lower than 1\% [37]. Then, the liquid phase can be drained from the test section and its volume determined. If the volume of the section containing the trapped fluid is known, the volume void fraction can be determined. The major difficulties of this method consist in the complete drainage of fluids with high viscosities and the time necessary for the set-up condition. Additionally, there is an inherent inaccuracy in the method due to changes of flow pattern while the valves are closing. Figure 1 illustrates the measurement of void fraction based on quick-closing valves technique. 


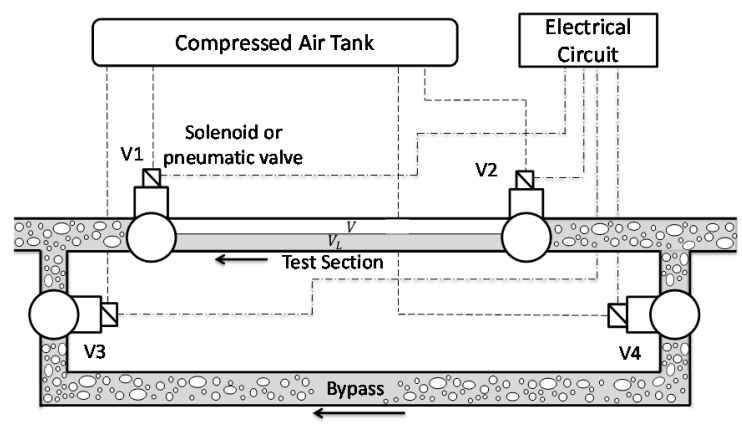

Figure 1. Measurement of void fraction based on quick-closing valves.

\subsection{Local Measurements (Needle Probe)}

The needle probe sensor consists of a phase detector emitting a two-state signal indicating which phase surrounds a sensing part of the tip. There are several designs of optical and electrical probe types with distinct size and geometry for different range of applications [38-43]. Figure 2 illustrates the schematic diagram of an optical and electrical probe. These sensors are mostly employed on liquid/gas applications, however it is also employed on liquid/liquid suspensions with limitation [44]. The phase detection is usually based on four techniques: refractive index, electrical conductivity and/or capacitance, thermal conductivity and electrochemical diffusivity [45]. The sensitive part of the sensor must be small when compared to the phase detected and the low time response is also important in order to obtain a reasonable result.

a) Optical probe

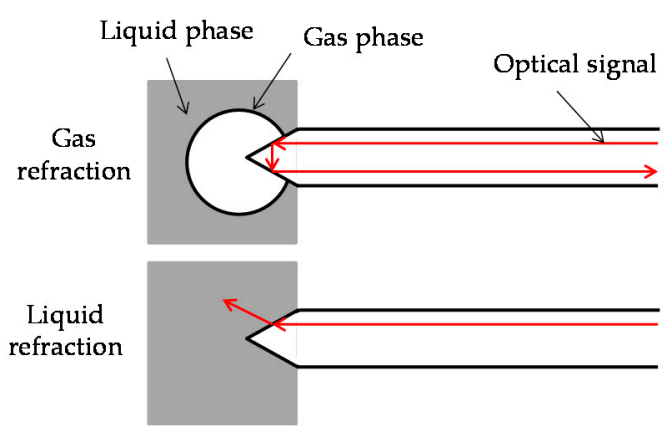

b) Electrical probe

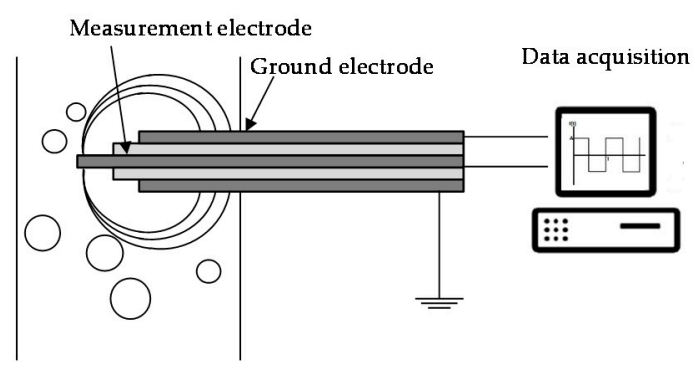

Figure 2. Schematic diagram of (a) optical probe and (b) electrical probe.

With optical sensors, light is emitted from a source on the tip of the probe, and reflected back to a sensor, which converts it into an electrical signal. Gas, with a low optical index, reflects a significant amount of light resulting in a large signal, while liquids provide low signals [43]. Then it can easily distinguish between gas and liquid phase. However, this technique may not properly identify the difference between oil and water.

An impedance probe measures the change of the resistivity and/or capacitance according to the phase in contact with the probe tip. In general, electric probes emit high frequency current and measure the amplitude of the signal in a small spherical region near the probe tip. The basic requirement is that the conductivity and/or capacitance values of the phases under study are significant different. The use of several probes can be employed to determine the superficial void fraction as in the wire-mesh technique.

\subsection{Wire-Mesh Sensor}

The wired mesh sensor was first introduced by Prasser et al. [46], and since then it has been successfully employed to investigate two-phase flow phenomena. The wire-mesh sensor essentially consists of two planes of wire grids electrodes stretched across the cross-section of a channel at 
an angle of $90^{\circ}$. The typical spacing of the wire planes is $2 \mathrm{~mm}$, as well as the distance between the electrodes [47]. This distance is also related to the spatial-temporal resolution. The electrodes measure an electrical property (conductivity or permittivity) in the gaps of all crossing points by applying a bipolar voltage pulse. Based on the bipolar voltage, the sensor is able to determine the instantaneous fluid distribution across the cross-section area. The wire-mesh sensor is able to perform void fraction and flow pattern measurements with a temporal resolution of $10 \mathrm{kHz}$ [48]. Furthermore, phase velocities can be determined by using two wire-mesh sensor by measuring the delay time between different wire planes by cross-correlation techniques [49]. Figure 3 illustrates a simplified scheme of wire-mesh measurement.

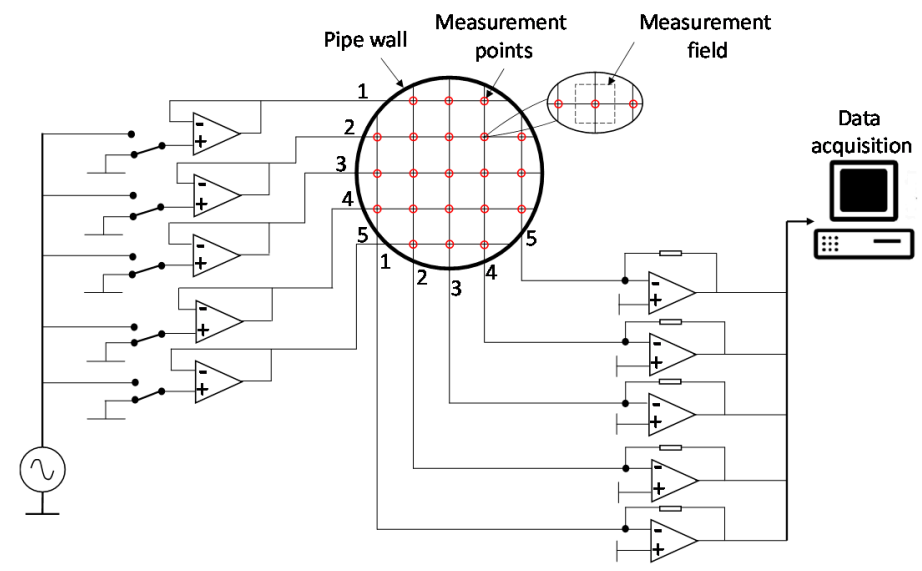

Figure 3. Scheme of a wire-mesh sensor with $5 \times 5$ electrodes.

One disadvantage of the wire-mesh sensor is its intrusive characteristic. According to Prasser et al. [46], this method may cause a significant pressure drop, in addition it also could modify the velocity and deform bubbles shape. A correction would be necessary if the temperature of the fluid changes during the experiment [49]. Due the intrusive characteristic the wire-mesh sensor is hardly applied in channels with reduced diameter. On the other hand, as reported by Peña and Rodriguez [50], the main advantage is the direct measurement of the phase fraction and is also being used as an aid for Computational Fluid Dynamics (CFD) simulations.

\subsection{Hard-Field Tomography}

The hard-field tomography technique allows the determination of the internal structure of an object by exposing it to a penetrating wave in a nondestructive way. Hard-field tomography includes ionizing radiation (X-ray, $\gamma$-ray and positron emission tomography) and magnetic resonance image (MRI) [24-26]. Figure 4 illustrates the three main elements of a tomography: the source of the wave, the detector arc to absorb the wave and a data acquisition circuit. The base of a tomography consists of directing waves towards an object from multiples orientations and measuring the attenuated beam intensity along a series of detectors. This attenuation of the signal is characterized by Beer-Lambert's law, Equation (1), which describes the attenuations as function of incident intensity, path length and material

$$
I=I_{0} \exp (-\mu \rho x)=I_{0} \exp (-\gamma x)
$$

where $I$ is the attenuated intensity of the beam, $I_{0}$ is the incident intensity, $\mu$ the absorption coefficient, $\rho$ the object density, $x$ the object width. The product $\rho \mu=\gamma$ is called the attenuation coefficient of the material. 


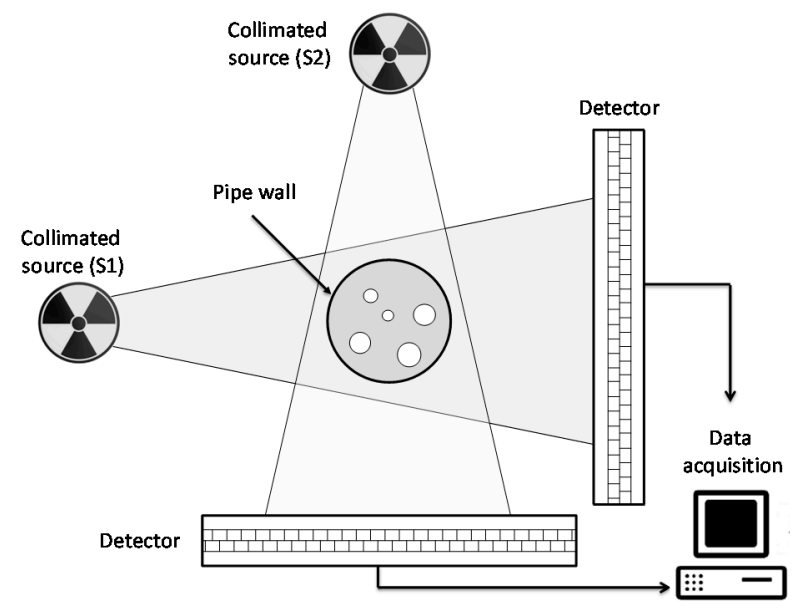

Figure 4. Principle of hard-field tomography.

\subsection{Electrical Impedance Tomography}

The electrical capacitance tomography (ECT) may be intrusive or nonintrusive method based on measurements of the impedance change due the flow distribution and concentration of the phases. This technique consists on measurement of electrical properties (resistance, capacitance or even both) between a set of electrodes placed around or within the flow. The fast response of the method makes possible to obtain information about instantaneous void fractions distributions across a pipe section. It is important to highlight that the capacitances and the permittivity distribution of dielectric materials is complex and nonlinear [51]. To overcome the possible difficulties due to different flow regimes, a higher number of electrode systems have been extensively used, varying its geometry (design) or spatial distribution. Figure 5 illustrates the main elements of an electrical impedance tomography.

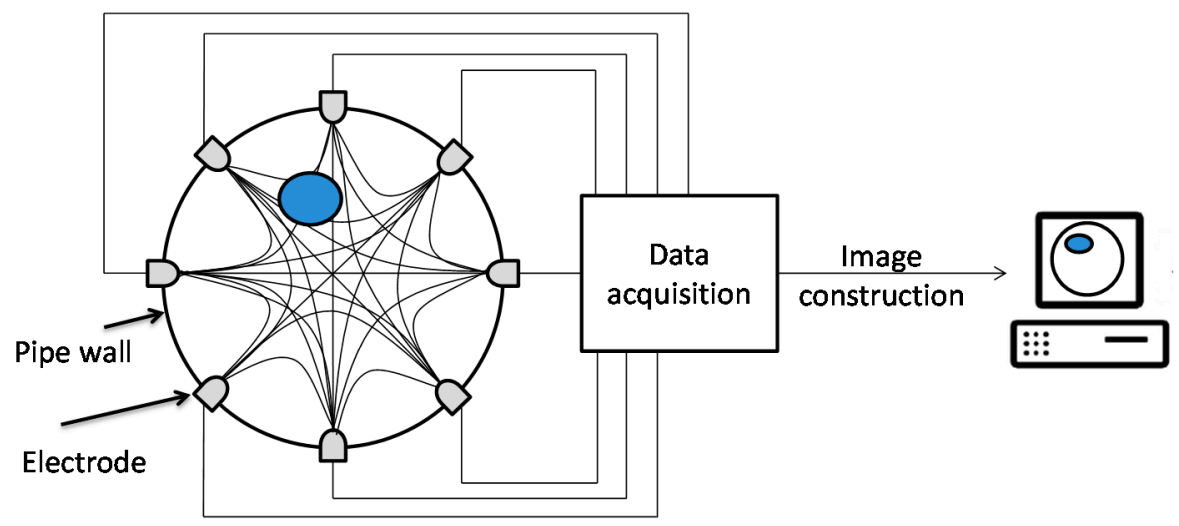

Figure 5. Typical intrusive electrical impedance tomography system with eight electrode sensors with sensing boundary.

According to Yang and Peng [52], there are two major problems in ECT: (i) forward problem: determine the interelectrode capacitances from permittivity by solving partial differential equations; (ii) inverse problem: determine the permittivity from capacitance measurements. Despite these issues, ECT has proved very important for situations where it is not possible a visual access to the flow or an intrusive measurement.

\subsection{Photographic Image Technique}

Differently from other methods, the use of photographed images gives direct information about the phase flow, such as bubble size, bubble shape and flow pattern. With these flow properties it is possible to determine additional information such as the void fraction or the phase's distribution $[53,54]$. 
For slug flow regime, the presence of disperse bubble is a challenge on the implementation of image processing [53]. It is important to highlight that this technique may result in an improper bubble tail boundary when it is followed by dispersed bubbles. According to Widyatama et al. [53], the error will increase as the amount of the dispersed bubble increases. To improve the technique multi vision systems have been recently used enabling the capture of images from different directions. With the advanced of image processing techniques, the reconstruction of a much more accurate flow patterns became possible. This allowed a more accurate void fraction measurement. It is important to highlight that the frequency of images acquisition and the image distortion by the pipe wall may result in some inaccuracy.

\subsection{PIV}

Particle Image Velocimetry (PIV) is a nonintrusive laser optical measurement technique for research into flow properties such as liquid velocity, bubble velocity, bubble size and void fraction [23]. PIV provides the instantaneous velocity vector in a cross-sectional of a flow. The basic idea in this method is the use of a light source (laser) in a cross-sectional area. The particles in this section would interact with light and the scattered light from the particles would be captured. In a two-phase flow, particles flow mainly with the liquid phase, allowing for the identification of the phases. Harada et al. [23] used PIV measurements on cavitation flow to determine the void fraction on the two-phase flow mixture. They observed near a nonslip homogenous flow and related the void fraction to PIV velocity measurements and flow areas.

\subsection{Ultrasound}

The ultrasonic method consists of an ultrasonic transducer with a piezoelectric that generates ultrasonic waves from an electric signal acting as emitter or a receiver. The ultrasound technique can be classified into three different groups: (i) transmission technique; (ii) Doppler technique; (iii) pulse-echo technique. The transmission technique measures the average void fraction based on the attenuation and delay of the ultrasonic pulse caused by the presence of bubbles [55], and it is also possible to measures the bubble velocity [56]. The Doppler technique allows to measure the velocity profile. A pulse-echo method measures the position of gas-liquid interface based on the reflection of the ultrasonic pulse, where the distance is obtained by measuring the transit time of the pulse. Figure 6 illustrates the different ultrasound technique principle. According to Povolny [55], the pulse-echo method can only be successfully applied under restricted conditions, such as large reflecting bubbles and low density of bubbles. This affirmation is corroborated by the studies of Da Silva. [45], which found that the ultrasound cannot distinguish very well between the bubble tail and the dispersed bubbles.

Transmission

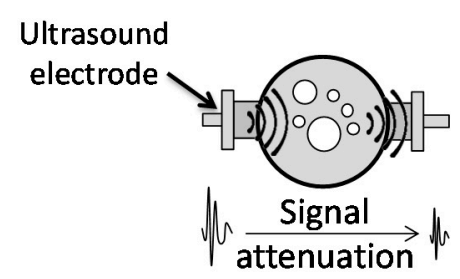

Doppler

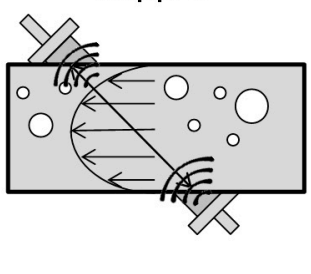

Pulse-echo

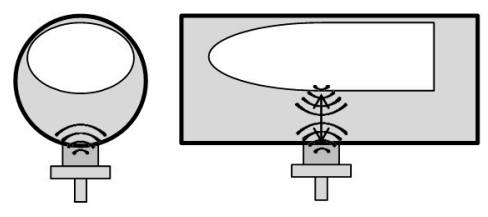

Figure 6. Illustration of ultrasound principle for transmission, Doppler and pulse-echo technique.

\subsection{Pressure Drop}

Many researchers sought for relations between pressure drop and void fraction along the years. Lockhart and Martinelli [7] developed the general correlation of pressure drop for two-phase flow. Wallis [57] fitted an equation to the plot of liquid hold up " $1-\alpha$ " against Lockhart and Martinelli " $X$ " parameter which was a function of the two-phase pressure drop [20]. Tang and Heindel [58] concluded that the pressure drop on a two-phase flow occurs, in part, by the friction between the fluid and the 
duct walls and, also, by the energy losses caused by the turbulence between liquid and gas phases, with the slip ratio, due the different velocities that the phases present.

For vertical two-phase flow, Jia et al. [20] proposed a method to measure the void fraction, by means of differential pressure measurements. The idea is to measure the pressure difference between two points along the height of a vertical tube and use this information to determine the mean density of the two-phase flow. Assuming a steady-state-developed two-phase flow, with a uniform cross-sectional area, the variation of pressure along a vertical tube is the sum of the hydrostatic component and the frictional one. Assuming upward flow this relation can be written as follows:

$$
\Delta P=\rho_{m} g h+F_{p}
$$

where $\rho_{m}$ is the mixture density, $h$ is the hydrostatic height between the differential pressure measurement taps, $g$ the gravitational acceleration and $F_{p}$ the friction pressure drop. The mixture density is related to the void fraction by

$$
\rho_{m}=(1-\alpha) \rho_{L}+\alpha \rho_{g}
$$

where $\rho_{L}$ is the liquid phase density and $\rho_{g}$ the gas liquid density and $\alpha$ the void fraction. The frictional pressure drop can be calculated by the Fanning friction factor, $C_{f}$ through the expressions:

$$
F_{p}=\frac{2 C_{f} \rho_{m} h v^{2}}{D}
$$

where $v$ is the liquid velocity. The viscosity used by the authors was approximated by the liquid phase.

Finally, combining Equations (2)-(4) the void fraction can be determined as follows:

$$
\alpha=1-\frac{\Delta P}{\rho_{L} g h}+\frac{2 C_{f} v^{2}}{g D}
$$

Jiu et al. [20] performed two-phase flow experiments to test the above procedure comparing the measured void fraction obtained by Equation (5) with wire-mesh technique and electrical resistance tomography. The authors observed that for void fractions above 0.2 the differential pressure method agreed well with the wire-mesh sensor.

\subsection{Methods Comparison}

In the context of void fraction measurements in small channels, new challenges arise due to the inherent difficult of fabrication of small components. When applying the measurements techniques in this condition the most important requirements that should be respected are:

- $\quad$ keep low uncertainty

- be capable of measure superficial or volumetric void fraction

- not intrusive

- $\quad$ able to measure instantaneous void fraction

These requirements come with higher costs for increasing reduction in channel diameter. The lower limit of the void fraction measurements in terms of channel diameter have been expanded in recent years. Channel diameter down to $0.5 \mathrm{~mm}$ has been measured [17,21].

Table 2 compares the previous discussed techniques considering these requirements in order to aid the selection of techniques for void fraction measurement in small-diameter channels. Quick-closing valves are still an available option, but with a higher cost associate with noncommercial microvalves that should have very low residual volume to keep a low uncertainty along measurements. Optical technique seems to aggregate the most characteristics to achieve all the above requirements and allow further reduction in channel diameter with lower cost and uncertainty compared to other techniques. 
In the next section, experimental void fraction data for small-diameter channels are identified and discussed considering the measurement techniques.

Table 2. Methods comparison.

\begin{tabular}{|c|c|c|c|c|}
\hline Technique & $\begin{array}{c}\text { Spatial } \\
\text { Resolution }\end{array}$ & $\begin{array}{l}\text { Temporal } \\
\text { Resolution }\end{array}$ & Costs & Observation \\
\hline Quick-closing valve & Good & No & Low & Intrusive, microchannel \\
\hline $\begin{array}{l}\text { Needle probes (electrical, } \\
\text { optical) }\end{array}$ & No & Good & Low & Intrusive, local measurement \\
\hline Ultrasound probe & No & High & Medium & Measures average void fraction \\
\hline $\begin{array}{l}\text { Optical (PIV, LDA, } \\
\text { videometry) }\end{array}$ & High & High & Medium & Low gas fraction \\
\hline $\begin{array}{l}\text { Hard-field tomography (X-ray, } \\
\gamma \text { - ray, PET, MRI) }\end{array}$ & Good & Low & High & Radiation protection \\
\hline Soft-field (EIT, ECT, ERT) & Low & High & Low & Nonlinear \\
\hline Wire-mesh sensor & High & High & Low & Intrusive \\
\hline
\end{tabular}

\section{Database}

The small channel database used on the present work is shown in Table 3 (microchannel data) and Table 4 (macrochannel data). The collected database is composed by a total of 2361 data points of R12, $\mathrm{R} 22$, R134a, R410A, propane and air-water for horizontal pipes with internal diameters ranging from 0.5 to $13.84 \mathrm{~mm}$. This database consists of both adiabatic and diabatic (evaporation and condensation) flow conditions in order to consider the effect of different heat transfer modes on void fraction.

Table 3. Database for void fraction for microchannel.

\begin{tabular}{lllllll}
\hline Authors & Technique & D [mm]/Geometry & Fluid & Type/Orientation & Data Points & Uncertainty \\
\hline Shedd [29] & Capacitive sensor & $0.508,1.19,2.92 / \mathrm{C}$ & R410A & Cond./H & 444 & $5 \%$ \\
Revellin et al. [21] & Light & $0.5 / \mathrm{C}$ & R134a & Evap./H & 10 & $\mathrm{n} / \mathrm{d}$ \\
Portillo et al. [27] & Capacitive sensor & $3.0 / \mathrm{C}$ & R410A & Evap./H & 64 & $\mathrm{n} / \mathrm{d}$ \\
Keinath [59] & Image & $0.51,1.0 .3 .0 / \mathrm{C}$ & R404A & Cond./H & 176 & $2-30.6 \%$ \\
Barreto et al. [32] & Resistive sensor & $1.2 / \mathrm{C}$ & Air-water & Adiab./V & 37 & $5 \%$ \\
\hline
\end{tabular}

H: horizontal; V: vertical; C: Circular channel; n/d: no data.

The collected data shown on Table 3 contain seven different diameters ranging from 0.5 to $3.0 \mathrm{~mm}$, and data on Table 4 contain 12 different diameters ranging from 4.26 to $13.84 \mathrm{~mm}$. According to the classification adopted by Kandlikar [60], using $3 \mathrm{~mm}$ as the threshold of macroscale and miniscale channels, 731 ( $31 \%$ of the present database) out of the 2361 data points can be classified into the miniscale category. The percentage and the number of data points discriminated by fluids are presented in Table 5. Among the four fluids involved in microchannel presented in Table 3, R404A and R410A are the main ones, contributing by $95 \%$. It is important to highlight that the void fraction data source of air-water and R134a flowing in microchannel available in the literature is reduced. On the other hand, for macrochannel, almost one-third of the data points are composed by R134a. The refrigerants R410A (33\%) and R22 (19\%) also have a significant contribution for the macroscale channel database. As can be observed in Tables 3 and 4, the uncertainty levels of individual database are not directly correlated with the type of measurement method. 
Table 4. Database for void fraction for macrochannel.

\begin{tabular}{|c|c|c|c|c|c|c|}
\hline Authors & Technique & $\mathrm{D}[\mathrm{mm}] /$ Geometry & Fluid & Type/Orientation & Data Points & Uncertainty \\
\hline Yashar et al. [14] & Quick-closing valves & $4.26,7.25,7.26 / \mathrm{C}$ & R134a, R410A & Evap. Adiab./H & 57 & $0.3 \%$ \\
\hline Srisomba et al. [16] & Quick-closing valves & $8.0 / \mathrm{C}$ & $\mathrm{R} 134 \mathrm{a}$ & Adiab./H & 117 & $1.2 \%$ \\
\hline Lips and Meyer [61] & Pressure drop & $8.38 / \mathrm{C}$ & $\mathrm{R} 134 \mathrm{a}$ & Cond. $/-90^{\circ}$ to $90^{\circ}$ & 6 & $\mathrm{n} / \mathrm{d}$ \\
\hline Olivier et al. [30] & Capacitive sensor & $8.38 / \mathrm{C}$ & $\mathrm{R} 134 \mathrm{a}$ & Cond. $/-90^{\circ}$ to $90^{\circ}$ & 23 & $2 \%$ \\
\hline Hashizume [10] & Quick-closing valves & $10.0 / \mathrm{C}$ & $\mathrm{R} 12, \mathrm{R} 22$ & Evap./H & 256 & $\mathrm{n} / \mathrm{d}$ \\
\hline Wilson [13] & Quick-closing valves & $6.12,8.89 / \mathrm{C}$ & Propane & Cond./H & 94 & $0.3-5.0 \%$ \\
\hline Canière [64] & Capacitive sensor & $8.0 / \mathrm{C}$ & R134a, R410A & Evap./H & 279 & $10 \%$ \\
\hline Graham [65] & Quick-closing valves & $7.04 / \mathrm{C}$ & $\mathrm{R} 134 \mathrm{a}, \mathrm{R} 410 \mathrm{~A}$ & Cond./H & 40 & $\mathrm{n} / \mathrm{d}$ \\
\hline Kopke [66] & Quick-closing valves & $6.04,7.04 / \mathrm{C}$ & R134a, R410A & $\begin{array}{l}\text { Cond. Adiab. } \\
\text { Evap./H }\end{array}$ & 44 & $10 \%$ \\
\hline Koyama et al. [15] & Quick-closing valves & $7.52 / \mathrm{C}$ & R134a & Adiab./H & 28 & $0.7-6.2 \%$ \\
\hline
\end{tabular}

H: horizontal; V: vertical; C: Circular channel; n/d: no data.

Table 5. Database distribution.

\begin{tabular}{ccccccccc}
\hline \multicolumn{2}{c}{ Diameter/Condition } & R134a & R404A & R410A & Propane & R12 & R22 & Air-Water \\
\hline \multirow{2}{*}{$\mathrm{d}<3.0 \mathrm{~mm}$} & Data points & 10 & 176 & 508 & $\mathrm{n} / \mathrm{d}$ & $\mathrm{n} / \mathrm{d}$ & $\mathrm{n} / \mathrm{d}$ & 37 \\
& $\%$ & 1.37 & 69.49 & 24.08 & $\mathrm{n} / \mathrm{d}$ & $\mathrm{n} / \mathrm{d}$ & $\mathrm{n} / \mathrm{d}$ & 5.06 \\
\hline \multirow{2}{*}{$\mathrm{d}>3.0 \mathrm{~mm}$} & Data points & 477 & $\mathrm{n} / \mathrm{d}$ & 549 & 117 & 104 & 323 & $\mathrm{n} / \mathrm{d}$ \\
& $\%$ & 29.26 & $\mathrm{n} / \mathrm{d}$ & 33.68 & 10.86 & 6.38 & 19.82 & $\mathrm{n} / \mathrm{d}$ \\
\hline \multirow{2}{*}{ All database } & Data points & 487 & 176 & 1057 & 177 & 104 & 323 & 37 \\
& $\%$ & 20.62 & 7.45 & 44.77 & 7.50 & 4.41 & 13.68 & 1.57 \\
\hline
\end{tabular}

n/d: no data.

Figure 7 shows the histograms of the experimental database present on Tables 3 and 4 and it also includes the cumulative percentage of the database. It can be seen from Figure $7 \mathrm{c}$ that the gas mass fraction database considered in this study is well distributed from low to high values, comprising almost all the possible flow patterns in gas-liquid two-phase flow. For the mass velocity, the majority of the data $(85 \%)$ are concentrated from low to intermediate values of mass flux $\left(500 \mathrm{~kg} \mathrm{~s}^{-1} \mathrm{~m}^{-2}\right)$. It should be highlighted that a reduced fraction of the results was obtained for low void fraction values, corresponding to only 132 data points (less than $6 \%$ of the database) for void fraction lower than $40 \%$. Moreover, half of the database is concentrated for void fraction ranging from 0.02 to 0.82 . Based on the data distribution observed in Figure 7 the flow patterns of the database are mainly concentrated in intermittent and annular flow regimes [3]. Stratified flow is much less probable to occur in this database [1-3]. 

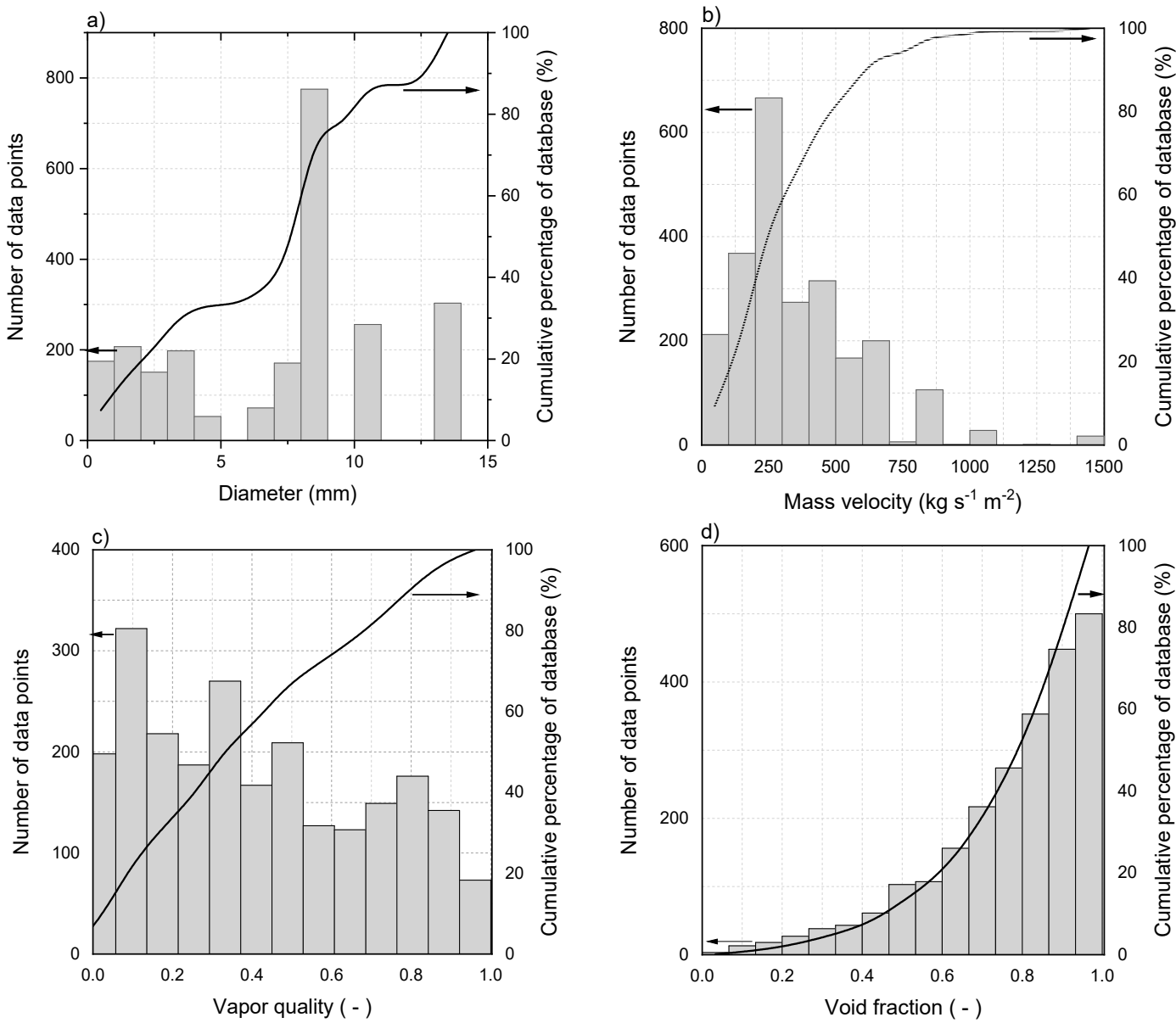

Figure 7. Distribution of the experimental data according to (a) internal diameter, (b) mass velocity, (c) vapor quality, and (d) void fraction.

\section{Void Fraction Correlations}

Void fraction correlations are usually classified into different groups related to the model they were based. These groups are: homogeneous models (the gas velocity is considered the same of the liquid's one), slip ratio models (based on the ratios evolving the mass fraction, gas and liquid densities and viscosities), drift flux models (based on a distribution parameter, which represents the nonuniformity of the stream, and the drift velocity, which is the relative velocity between the gas velocity and the two-phase velocity), $K_{\alpha h}$ models and miscellaneous or empiric models (obtained empirically) [8]. An important factor to emphasize is that the majority of void fraction correlations were developed using macrochannels database and cannot assure reliable results for microchannels conditions.

\subsection{Correlation Description}

Many researchers performed a verification of a large number of correlations and models present at the literature along the time. Based on several of these reviews $[2,6,8]$, some of the well-evaluated correlations are described in this work. The homogenous model provides a correlation that supposes the same velocity between the gas and the liquid flows, so, for flow configurations where there is a large difference between these velocities (as churn and annular), these models are not recommended. The homogeneous model provides the maximum value for a two-phase flow void fraction in flow configurations with gas velocity higher than liquid velocity (slip ratio above one). Lockhart and Martinelli proposed a slip ratio model correlation. The database was obtained for several air-liquid combinations in adiabatic circular ducts with 1.5 to $25.8 \mathrm{~mm}$ of diameter. 
Hughmark [67] developed a correlation based on drift flux models, with a database for air-oil, air-water and glycerine-water as fluids in nonadiabatic horizontal flow from 6.35 to $22.1 \mathrm{~mm}$ diameter. Wallis [57] proposed a miscellaneous correlation based on the Lockhart-Martinelli [7] model considering air-liquid combinations in an adiabatic duct from 1.5 to $25.8 \mathrm{~mm}$ diameter. Rouhani and Axelsson [68] adjusted a drift flux model correlation proposed by Zuber and Findlay [69]. Their database was obtained for steam-water on evaporation conditions in small rectangular ducts. Dix [70] proposed a drift flux model correlation based in tests with R114 in horizontal tubes. Chisholm [71] developed a slip ratio model correlation based on experiments with steam-water on evaporation conditions and air-water in ducts with $2.5 \mathrm{~mm}$ in diameter. Domanski and Didion [72] proposed a miscellaneous correlation based on the Lockhart-Martinelli [7] model considering air-liquid combinations in adiabatic tubes with 1.5 to $25.8 \mathrm{~mm}$ in diameter. Spedding and Chen [73] proposed a slip ratio model correlation with database for air-water in upward and downward inclined tubes with $4.54 \mathrm{~mm}$ in diameter. Kariyasaki et al. [74] developed a miscellaneous model correlation based on tests with air-water in isothermal ducts with 1.0 to $4.9 \mathrm{~mm}$ in diameter. Graham et al. [75] proposed a miscellaneous correlation based on the homogenous model with database for R134a and R410a (stratified and annular flow) on evaporation and condensation conditions in adiabatic, horizontal and smooth tubes with 4.3 to $6.1 \mathrm{~mm}$ in diameter. Niño et al. [76] developed a miscellaneous correlation based on the Lockhart-Martinelli [7] model. The database was obtained for R410a, R134a and air-water (annular flow) in adiabatic ducts with 1.54 and $1.02 \mathrm{~mm}$. Kawahara et al. [77] proposed a K $\alpha \mathrm{h}$ model correlation using the results obtained from experiments with water-nitrogen and ethanol-water-nitrogen in adiabatic ducts with 0.1 to $0.251 \mathrm{~mm}$ in diameter. Woldesemayat and Ghajar [5] adjusted the Dix [70] model considering the effect of the tube inclination. They used a database with combinations between air, water, kerosene and natural gas in 12.7 to 102.26 in diameter ducts. Zhang et al. [78] proposed a drift flux model correlation with a new distributed parameter considering that the drift velocity is equals to zero in microchannels. The database was obtained for combinations between water and R113 (liquids) and air and nitrogen (gases) in adiabatic ducts with 0.2 to $4.9 \mathrm{~mm}$ in diameter. Shedd [29] proposed a miscellaneous correlation based on the homogenous model with database for R410a in adiabatic and horizontal tubes from 0.508 and $2.92 \mathrm{~mm}$ in diameter. Cioncolini and Thome [6] developed a miscellaneous model correlation based on experiments with steam-water, R410a on evaporation conditions, air-water, argon-water, air-water-alcohol, air-alcohol and air-kerosene in adiabatic circular and noncircular ducts with 1.05 to $45.5 \mathrm{~mm}$ in diameter. $\mathrm{Xu}$ and Fang [8] proposed a correlation based on Chisholm [71] correlation (slip ratio type). The database was obtained for R11, R12, R22, R134a and R410a in ducts with 0.5 to $10 \mathrm{~mm}$ in diameter. Kanizawa and Ribatski [79] developed a miscellaneous type correlation based on the principle of minimum kinetic energy. The database was obtained for R134a, R235fa and R600a in horizontal and vertical tubes with 0.508 to $50.8 \mathrm{~mm}$ in diameter. Tibiriçá et al. [2] developed a slip ratio type correlation using a database with water, nitrogen, R134a, R113, R12, R123, R236fa, R245fa and R1234ze in adiabatic and horizontal tubes with annular, churn, slug and bubble flow patterns and 0.24 to $6.92 \mathrm{~mm}$ in diameter. All correlations mentioned above are presented on Table 6 . 
Table 6. Summary of the prediction method for void fraction evaluated on the current study.

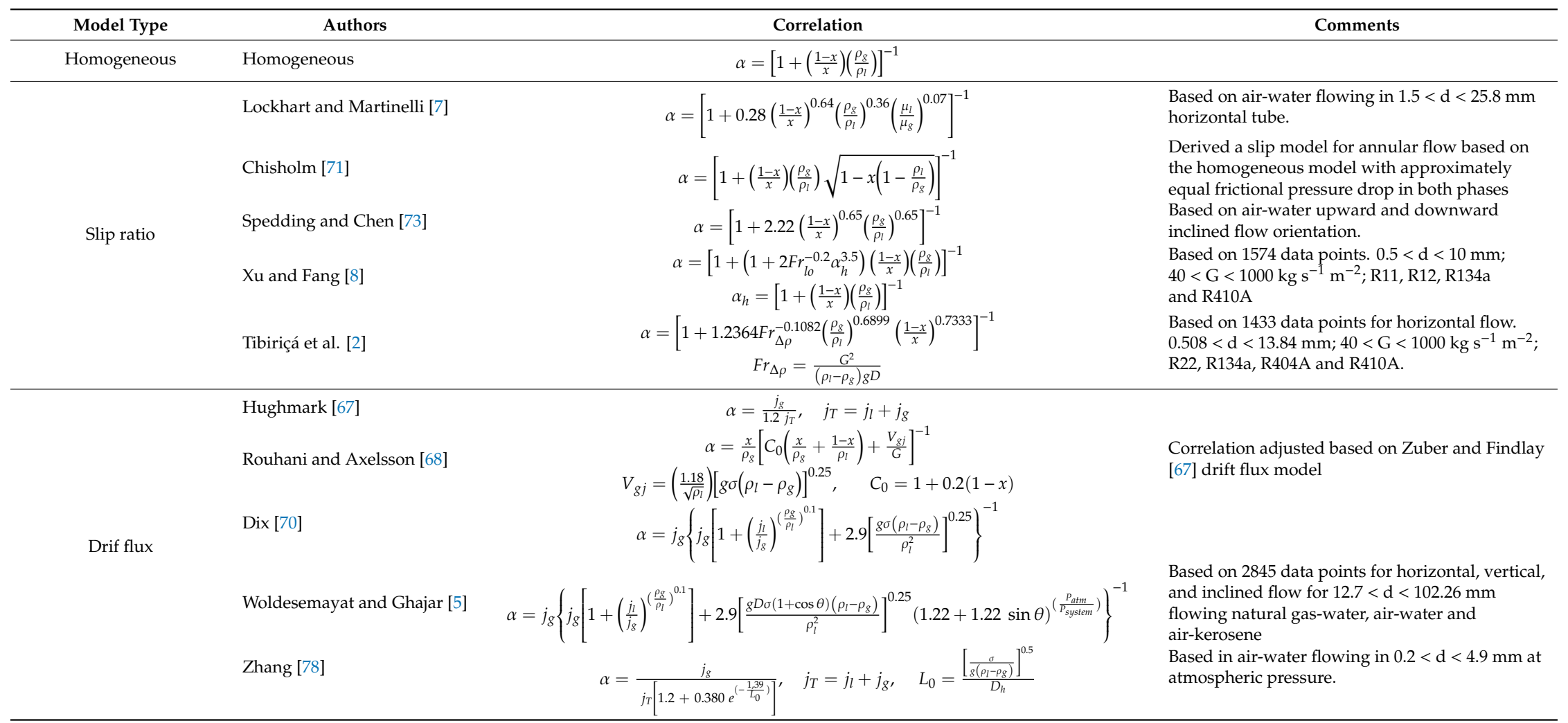


Table 6. Cont

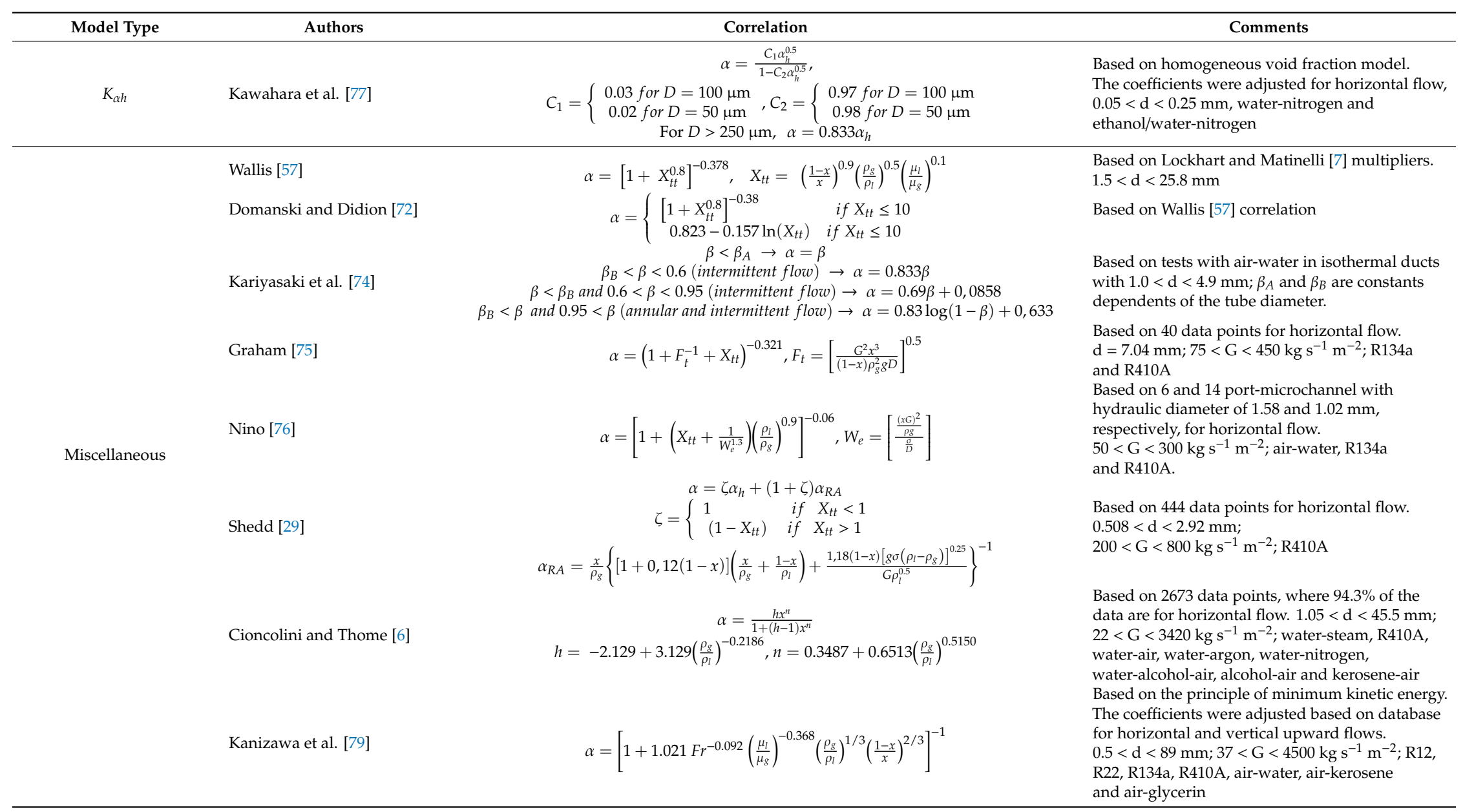


In Table $6, x$ is the gas mass fraction; $\rho_{g}$ and $\rho_{l}$, the densities of gas and liquid phases; $\mu_{g}$ and $\mu_{l}$, the viscosities of gas and liquid phases; $F r$, the Froude number; $\alpha_{h}$, the void fraction calculated through the homogeneous model; $G$, the mass flux; $g$, the acceleration of gravity; $D$, the inner diameter; $j_{g}$ and $j_{l}$, the superficial velocity of gas and liquid; $j_{T}$, the two-phase mixture velocity; $\sigma$, the surface tension; $\theta$, the tube inclination angle; $P$, the pressure; Lo, the nondimensional Laplace constant; $D_{h}$, the hydraulic diameter; $X_{t t}$, the Lockhart-Martinelli parameter; $\beta_{A}$ and $\beta_{B}$, constants depending on the tube diameter; $F_{t}$, the Froude rate; $W e$, the Weber number; and $\alpha_{R A}$, the void fraction calculated through the Rouhani and Axelsson [68] model.

\subsection{New Correlation}

The objective for this section is to propose a new drift flux type void fraction correlation adjusted with 731 microchannel data points and to analyze its performance against the whole database, as well as the microchannel and macrochannel points. This will indicate if correlations from literature can be further improved for small diameter channel conditions. Drift flux correlations predict the void fraction considering the gas superficial velocity, $j_{g}$, the two-phase mixture velocity, $j_{T}$, the distribution parameter, $C_{0}$ and the drift velocity, $V_{g j}$, according to the drift flux model originally proposed by Zuber and Findlay [69] as shown in Equation (6).

$$
\alpha=\frac{j_{g}}{C_{0} j_{T}+V_{g j}}
$$

The main challenges in the development of a correlation of this type is the adjustment and the modeling of the parameters $V_{g j}$ and $C_{0}$, that represent the difference between the gas velocity and the two-phase mixture one and the flow nonuniformity, respectively [8]. For this new correlation, the models that presented more accurate and balanced results considering the conditions of the database were the ones with a distribution parameter based on Dix [70]. A new relation for drift velocity is proposed in this work, which is a modified version of Dix drift velocity [70], but with an additional degree of freedom for numerical regression on the density ratio term. The new void fraction correlation is presented below.

$$
\alpha=\frac{j_{g}}{j_{g}\left[1+\left(\frac{j_{l}}{j_{g}}\right)^{\left.\left(\frac{\rho g}{\rho_{l}}\right)^{0.0752}\right]+1.24\left(\frac{g \sigma}{\rho_{l}}\right)^{1 / 4}\left(\frac{\rho_{l}-\rho_{g}}{\rho_{l}}\right)^{1.1920}}\right.}
$$

Comparing Equation (7) to Equation (6) the distribution parameter is given by

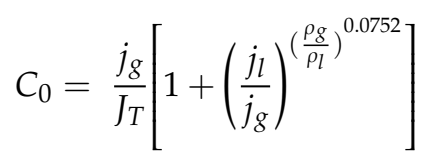

and the drift velocity given by

$$
V_{g j}=1.2402\left(\frac{g \sigma}{\rho_{l}}\right)^{1 / 4}\left(\frac{\rho_{l}-\rho_{g}}{\rho_{l}}\right)^{1.1920}
$$

where $j_{l}$ is the liquid phase superficial velocity, $\rho_{g}$ is the gas phase density, $\rho_{l}$ is the liquid phase density, $\sigma$ is the surface tension, and $g$ the gravitational acceleration. Both the distribution parameter and the drift velocity are dimensional consistent in the new correlation. Distribution parameter is a dimensionless variable and the drift flux has unit of velocity $[\mathrm{m} / \mathrm{s}]$. 


\subsection{Results}

The parameters employed for the evaluation and comparison of the correlation's performance were the mean absolute deviation $(\epsilon)$ and the fraction of the experimental data predicted within a mean absolute deviation smaller than $10 \%\left(\lambda_{10 \%}\right)$. The parameters are defined as follows:

$$
\epsilon=\frac{1}{N} \sum_{i=1}^{N}\left|\frac{\alpha_{\text {experimental }, i}-\alpha_{\text {estimated }, i}}{\alpha_{\text {experimental }, i}}\right|
$$

where $N$ is the number of data points considered in the analysis. Tables 7-9 show the comparison between the correlations analyzed with the full database, and the macro and microchannel database, respectively, in terms of $\lambda_{10 \%}$ and $\epsilon$. The new correlation presented the best results for microchannel points.

Table 7. Mean absolute error and the percentage of the whole database with error up to $10 \%$ for the correlation evaluated.

\begin{tabular}{lll}
\hline Ahors & $\boldsymbol{\epsilon} \mathbf{( \% )}$ & $\lambda_{\mathbf{1 0} \%} \mathbf{( \% )}$ \\
\hline Homogeneous & 15.91 & 51.35 \\
Lockhart and Martinelli [7] & 14.89 & 66.65 \\
Hughmark [67] & 12.51 & 45.05 \\
Wallis [57] & 16.03 & 68.64 \\
Rouhani and Axelsson [68] & 8.88 & 76.08 \\
Dix [70] & 11.44 & 63.02 \\
Chisholm [71] & 8.28 & 78.57 \\
Domanski and Didion [72] & 15.36 & 68.81 \\
Spedding and Chen [73] & 15.31 & 39.77 \\
Kariyasaki et al. [74] & 15.70 & 29.75 \\
Graham [75] & 11.08 & 76.54 \\
Nino [76] & 29.44 & 55.49 \\
Kawahara et al. [77] & 44.45 & 11.83 \\
Woldesemayat and Ghajar [5] & 7.98 & 81.11. \\
Zhang [78] & 13.05 & 43.66 \\
Shedd [29] & 13.57 & 62.76 \\
Cioncolini and Thome [6] & 13.37 & 66.57 \\
Xu and Fang [8] & 8.22 & 80.60 \\
Kanizawa et al. [79] & 9.23 & 82.54 \\
Tibiriçá et al. [2] & 8.16 & 82.67 \\
New correlation (Equation (7)) & 7.90 & 79.46 \\
\hline
\end{tabular}

The correlations which had the best results for the whole database, in terms of $\epsilon$, were the new proposed correlation, followed by Woldesemayat and Ghajar [5], Tibiriçá et al. [2], Xu and Fang [8], Chisholm [71] and Rouhani and Axelsson [68] correlations. A comparison between the void fraction of experimental data and the predicted values by these correlations, including the new one, is presented on Figure 8. Note that the best results occur in regions of high void fractions. In terms of $\lambda_{10 \%}$, the best predictions were provided by Tibiriçá et al. [2], followed by Kanizawa et al. [79], Woldesemayat and Ghajar [5], Xu and Fang [8], the new correlation and Chisholm [71]. 
Table 8. Mean absolute error and the percentage of macrochannel data with error up to $10 \%$ for the correlation evaluated.

\begin{tabular}{lll}
\hline Authors & $\boldsymbol{\epsilon} \mathbf{( \% )}$ & $\lambda_{\mathbf{1 0} \mathbf{\%}} \mathbf{( \% )}$ \\
\hline Homogeneous & 16.47 & 46.75 \\
Lockhart and Martinelli [7] & 11.70 & 67.48 \\
Hughmark [67] & 11.70 & 49.69 \\
Wallis [57] & 11.83 & 70.60 \\
Rouhani and Axelsson [68] & 8.15 & 80.31 \\
Dix [70] & 10.99 & 65.28 \\
Chisholm [71] & 7.16 & 84.05 \\
Domanski and Didion [72] & 11.66 & 70.18 \\
Spedding and Chen [73] & 12.82 & 48.04 \\
Kariyasaki et al. [74] & 14.93 & 33.19 \\
Graham [75] & 7.14 & 81.96 \\
Nino [76] & 20.61 & 61.59 \\
Kawahara et al. [77] & 40.06 & 14.91 \\
Woldesemayat and Ghajar [5] & 6.78 & 84.29 \\
Zng [78] & 11.70 & 49.69. \\
Shedd [29] & 13.75 & 60.98 \\
Cioncolini and Thome [6] & 11.65 & 66.07 \\
Xu and Fang [8] & 7.22 & 83.62 \\
Kanizawa et al. [79] & 6.99 & 86.56 \\
Tibiriçá et al. [2] & 6.47 & 85.83 \\
New correlation (Equation (7)) & 7.04 & 81.78 \\
\hline
\end{tabular}

Table 9. Mean absolute error and the percentage of microchannel data with error up to $10 \%$ for the correlation evaluated.

\begin{tabular}{lll}
\hline Authors & $\boldsymbol{\epsilon} \mathbf{( \% )}$ & $\lambda_{\mathbf{1 0} \% \mathbf{( \% )}}$ \\
\hline Homogeneous & 14.66 & 61.55 \\
Lockhart and Martinelli [7] & 21.95 & 64.84 \\
Hughmark [67] & 14.29 & 34.78 \\
Wallis [57] & 25.35 & 65.49 \\
Rouhani and Axelsson [68] & 10.50 & 66.71 \\
Dix [70] & 12.41 & 58.02 \\
Chisholm [71] & 10.76 & 66.44 \\
Domanski and Didion [72] & 23.53 & 65.76 \\
Spedding and Chen [73] & 20.82 & 65.76 \\
Kariyasaki et al. [74] & 17.42 & 22.15 \\
Graham [75] & 19.80 & 64.54 \\
Nino [76] & 48.99 & 41.98 \\
Kawahara et al. [77] & 54.16 & 5.03 \\
Woldesemayat and Ghajar [5] & 10.63 & 74.05 \\
Zhang [78] & 16.04 & 30.30 \\
Shedd [29] & 13.16 & 66.71 \\
Cioncolini and Thome [6] & 17.18 & 67.66 \\
Xu and Fang [8] & 10.43 & 73.91 \\
Kanizawa et al. [79] & 14.17 & 73.64 \\
Tibiriçá et al. [2] & 11.92 & 75.68 \\
New correlation (Equation (7)) & 9.80 & 74.32 \\
\hline
\end{tabular}



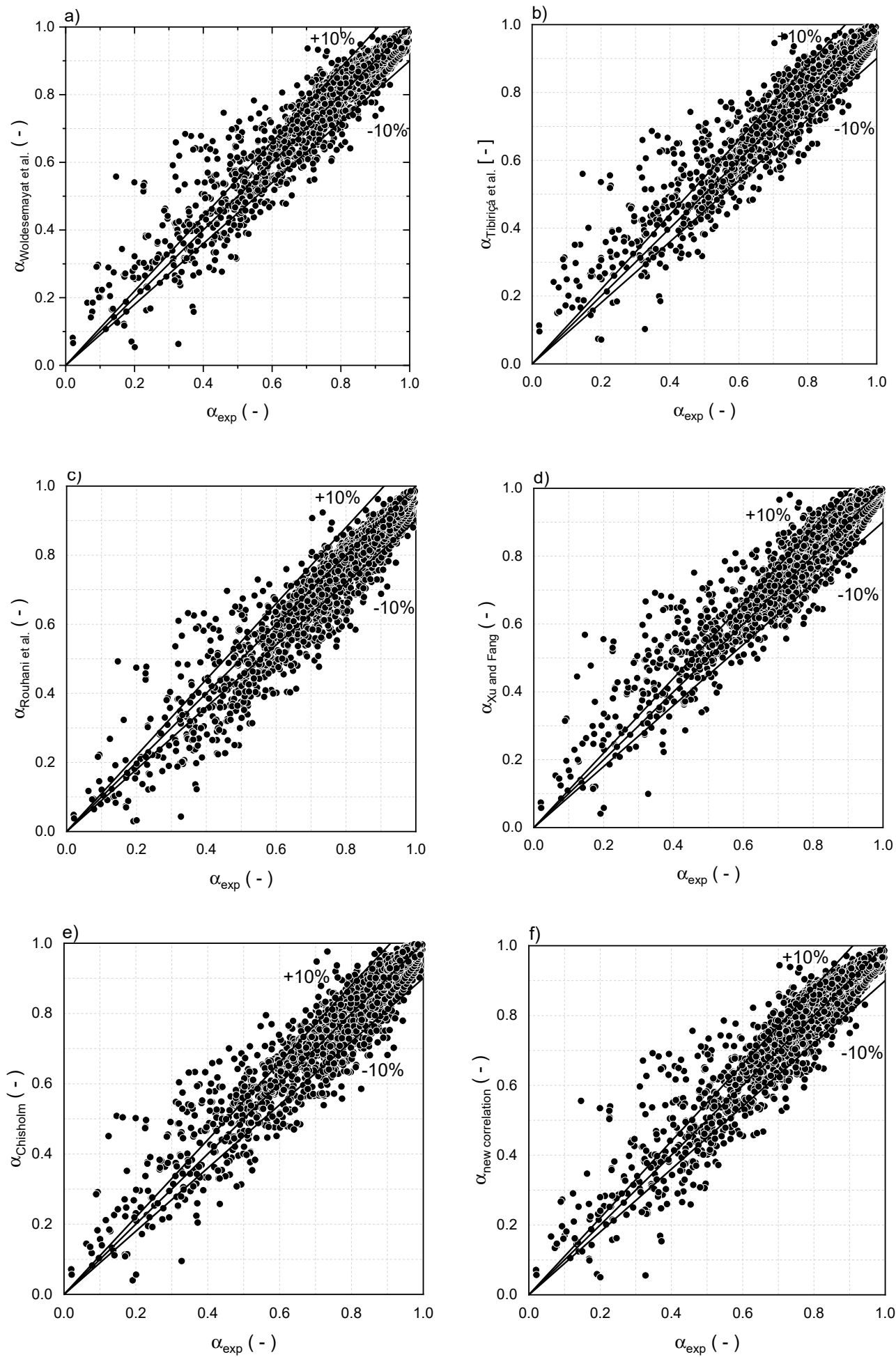

Figure 8. Comparison between the void fraction experimental data and the predicted data of (a) Woldesemayat et al. [5], (b) Tibiriçá et al. [2], (c) Rouhani and Axelsson. [68], (d) Xu and Fang [8], (e) Chisholm [71], and (f) new correlation.

For the macrochannel database (Table 4), the best correlations according to $\epsilon$ were provided by Tibiri, ${ }_{3} c^{\prime}$ a et al. [2], Woldesemayat and Ghajar [5], Kanizawa et al. [79], the new correlation, Graham [75] and Chisholm [71]. In terms of $\lambda_{10 \%}$, they were Kanizawa et al. [79], Tibiri ${ }_{3} c^{\prime}$ a et al. [1], Woldesemayat and Ghajar [5], Chisholm [71], Xu and Fang [8] and Graham [75]. 
Using the microchannel database, the best correlations according to $\epsilon$ were the new correlation, Xu and Fang [8], Rouhani and Axelsson [68], Woldesemayat and Ghajar [5], Chisholm [71] and Tibiri ${ }_{3} c^{\prime} a$ et al. [1]. In terms of $\lambda_{10 \%}$, the best predictions were given by Tibiri, ${ }_{5}$ 'a et al. [1], followed by the new proposed correlation, Woldesemayat and Ghajar [5], Xu and Fang [8], Kanizawa et al. [79] and Cioncolini and Thome [6].

From the above results it can be noticed that the new correlation has a very good performance also for the lower range of macroscale region, even when not using the macrochannel experimental data for the numerical regression. This good performance can be related to the format used for regression and due to the flow patterns on the macroscale database are mainly the same ones as in the microscale database collected in this work (bubbles, intermittent and annular)

Tables 10 and 11 present the mean absolute error between the results provided by the new correlation and each database evaluated (according to Tables 3 and 4), for microchannel and macrochannel, respectively. Note that the new correlation performed consistently for both conditions. For microchannel, the major and the minor errors are $16.17 \%$ and $4.75 \%$, respectively, while, for macrochannel data, these values are $18.37 \%$ and $1.94 \%$. If the predictions in Tables 10 and 11 are compared to the uncertainty of the experimental data in Tables 3 and 4 , a direct relation is not clear. The same occurs for the channel inclination, showing that the new correlation could predict with the similar error both horizontal and vertical tubes. From these results it can be concluded that, for void fraction, the transition from microscale to macroscale [80] has a smooth behavior with these conditions.

Table 10. Mean absolute error between the new correlation and each database for microchannel tested.

\begin{tabular}{ll}
\hline Authors & $\boldsymbol{\epsilon} \mathbf{( \% )}$ \\
\hline Shedd [29] & 6.98 \\
Revellin et al. [21] & 4.75 \\
Portillo et al. [27] & 9.55 \\
Keinath [59] & 16.17 \\
Barreto et al. [32] & 14.95 \\
\hline
\end{tabular}

Table 11. Mean absolute error between the new correlation and each database for macrochannel tested.

\begin{tabular}{ll}
\hline Authors & $\boldsymbol{\epsilon} \mathbf{( \% )}$ \\
\hline Yashar et al. [14] & 2.41 \\
Srisomba et al. [16] & 18.37 \\
Lips and Meyer [61] & 3.64 \\
Milkie et al. [62] & 6.87 \\
Olivier et al. [30] & 1.94 \\
Hashizume [10] & 5.16 \\
Wilson [13] & 3.75 \\
Wojtan [63] & 7.96 \\
De Kerpel et al. [31]. & 2.70 \\
Canière [64] & 6.06 \\
Graham [65] & 6.42 \\
Kopke [66] & 10.06 \\
Koyama et al. [15] & 6.05 \\
\hline
\end{tabular}

Figure 9, is a comparison between the experimental data of Portillo [27], which is part of the database, against the homogeneous model, the new correlation and the best ranked correlations from Tables 7-9. 


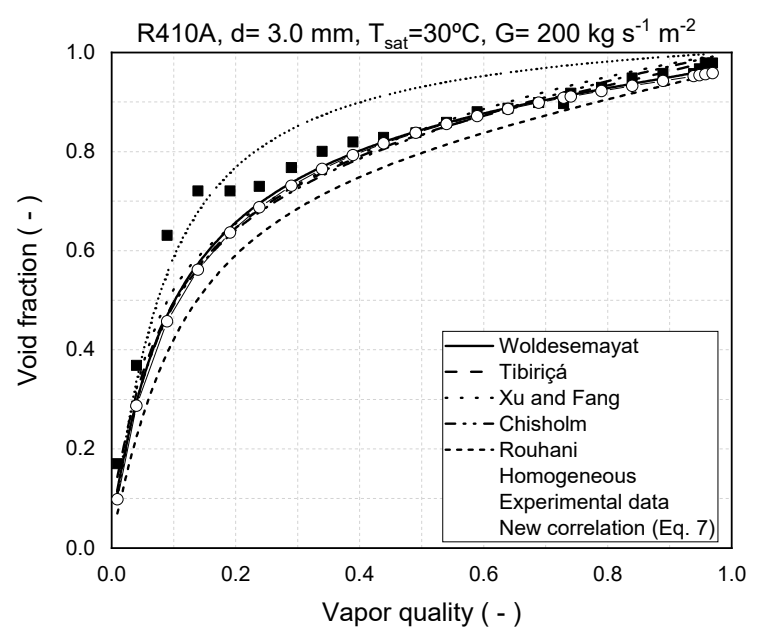

Figure 9. Comparison between experimental data of Portillo [27] and correlations predicted data.

Figure 10 presents the results for the slip ratio factor, Equation (11), calculated for the new correlation and the other six best-ranked correlations. Note that the slip ratio from the new correlation, from Tibiriçá et al. [2] and from Woldesemayat and Ghajar [5] all have a similar behavior. The slip ratio determined from the new correlation and from Woldesemayat and Ghajar [5] presenting higher values for vapor quality above $60 \%$. The same conclusion of Tibiriçá et al. [2] can be observed from these results, that of modeling slug flows as a nonslip flow pattern requires some caution, because the slip ratio at this condition is higher than one. The correlation of Rouhani and Axelsson [68] provided higher values of slip ratio, $\mathrm{Xu}$ and Fang [8] provided lower values. Chisholm [71] correlation presented higher slip ratios for low and intermediary vapor quality but it predicts lower slip ratios for higher vapor quality. The slip ratio given by the correlation of Chisholm [71] and $\mathrm{Xu}$ and Fang [8] gave considerably lower values of slip ratio for vapor quality close to one. It is clear from Figure 10 that the slip ratio local trends from these correlations can be considerably different, indicating that local phase velocities prediction could be badly predicted depending on the used correlation.

$$
S=\frac{\frac{1}{\alpha}-1}{\left(\frac{\rho_{v}}{\rho_{l}}\right)\left(\frac{1-x}{x}\right)}
$$

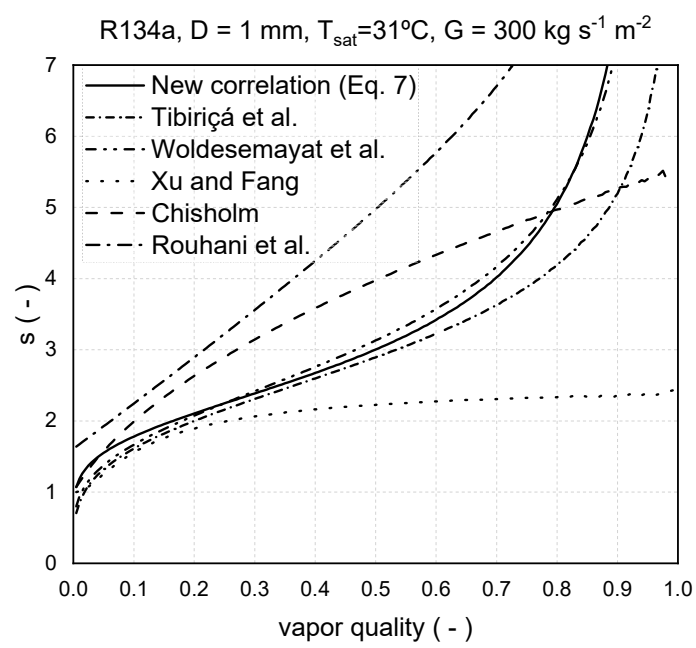

Figure 10. Comparison between the slip ratio calculated with the new correlation and the best ones observed from the literature. 
Figures 11 and 12 presents additional nondimensional parameters $\left(C_{0}\right.$ and $\left.V_{g j} / j_{T}\right)$ as a function of the vapor quality for the new correlation at the same conditions of Figure 11. The distribution parameter, $C_{0}$, reflects how the velocity profile and the void fraction are locally distributed along the channel radius. In flow boiling situations there are nucleation sites along the wall which affect the distribution parameter, mainly for low vapor qualities. As shown in Figure 13, the ratio of drift velocity by total superficial velocity, $j_{T}$, is always positive, showing that the in-situ gas velocity is always higher than the total superficial velocity.

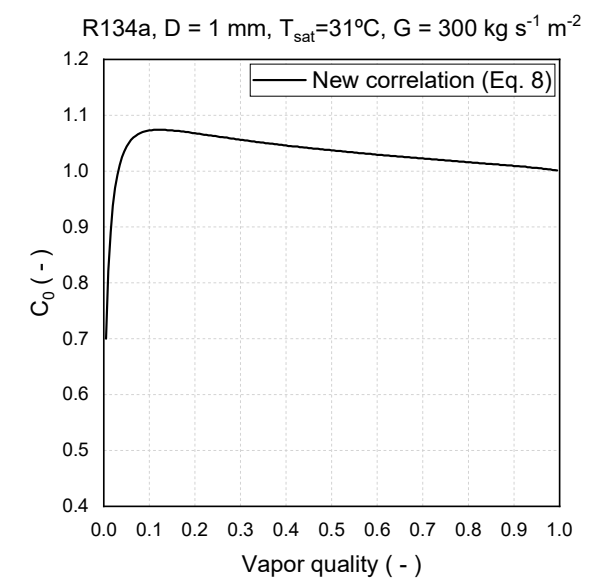

Figure 11. Distribution parameter in function of the quality.

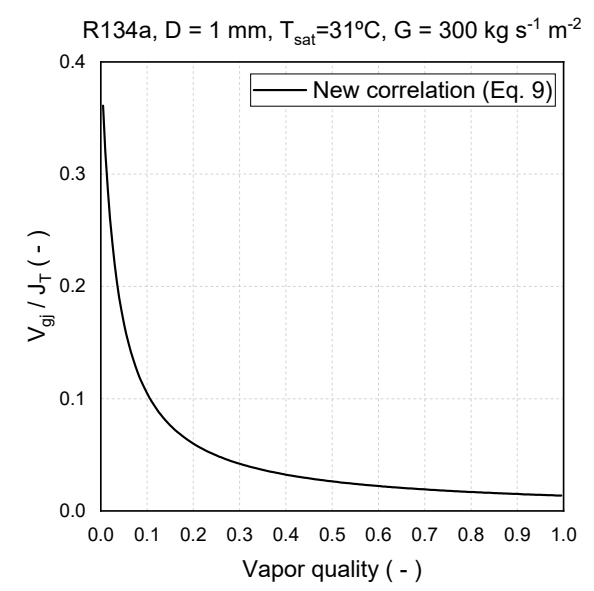

Figure 12. Ratio between the drift velocity and the mixture velocity in function of the quality.

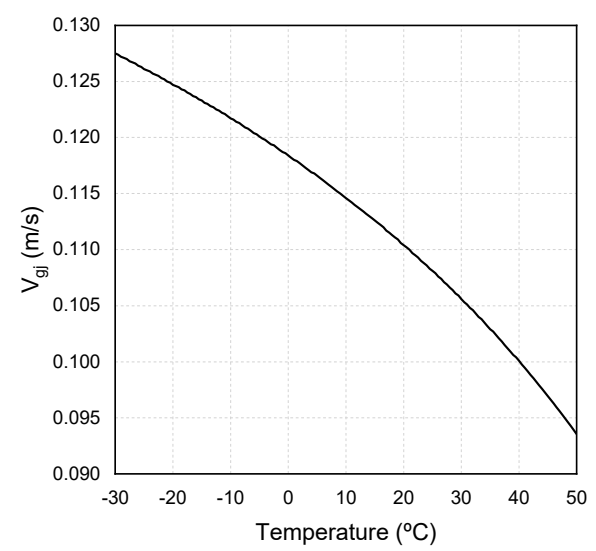

Figure 13. Drift velocity in function of the saturation temperature for R134a. 
Finally, Figure 13 presents the drift velocity as function of the saturation temperature, for the refrigerant $\mathrm{R} 134 \mathrm{a}$, from -30 to $50^{\circ} \mathrm{C}$, which is an interesting temperature range for applications in refrigeration systems, involving low back pressure (LBP) to high back pressure (HBP) applications. Note that the drift velocity decreases with the temperature increasing.

\section{Conclusions}

A study of void fraction measurement techniques, experimental databases and correlations for two-phase flows in small-diameter channels was performed and led to the following conclusions:

- In total, 18 measurement techniques for two-phase void fraction methods have been identified in the literature, classified in four main groups according to their measurement principle (mechanical, optical, electrical and ionizing radiation) and evaluated for their suitability for microchannel measurements.

- Optical void fraction measurement techniques seem to aggregate most of the characteristics needed for high quality void fraction measurements in microchannels, allowing further reduction in channel diameter with lower cost and lower uncertainty compared to other techniques.

- A large void fraction database consisting of diabatic and adiabatic experimental data from the literature has been obtained for small-diameter channels $(0.5<\mathrm{D}<13.84 \mathrm{~mm})$. This database was used for comparing well know void fraction correlations from literature against new proposed ones.

- A new drift flux void fraction correlation was numerically adjusted with microchannel database containing 731 datapoints $(0.5<\mathrm{D}<3.0 \mathrm{~mm})$ to test if predictions could be further improved. The new correlation could best predicted microchannel database and also the complete small channel diameter database of 2361 datapoints $(0.5<\mathrm{D}<13.84 \mathrm{~mm})$ with mean absolute error of $7.9 \%$. From the observed performance of the new correlation it can be concluded that the optimization of void fraction correlations for small scale diameters channels has not yet reached the limit and there is still space for improvement for new correlations, mainly in microchannels conditions.

Author Contributions: Data analysis, methods and writing: Á.R.G., E.d.S.F., D.G.C., G.S., R.M.O. Supervision and text integration: C.B.T. All authors have read and agreed to the published version of the manuscript.

Funding: The authors are thankful for Coordination for the Improvement of Higher Education Personnel (CAPES, Finance Code 001), National Council for Scientific and Technological Development (CNPq), Research and Industrial Improvement Foundation (FIPAI) and São Paulo Research Foundation (FAPESP proc. 2016/09509-1) for funding researches that have contributed to this study.

Acknowledgments: The authors are thankful for Angela Pregnolato Giampedro for the support on the revision of the manuscript.

Conflicts of Interest: The authors declare no conflict of interest.

\section{References}

1. Tibiriçá, C.B.; Ribatski, G. Flow boiling phenomenological differences between micro-and macroscale channels. Heat Transf. Eng. 2015, 36, 937-942. [CrossRef]

2. Tibiriçá, C.B.; Rocha, D.M.; Sueth, I.L.S., Jr.; Bochio, G.; Shimizu, G.K.K.; Barbosa, M.C.; dos Santos Ferreira, S. A complete set of simple and optimized correlations for microchannel flow boiling and two-phase flow applications. Appl. Therm. Eng. 2017, 126, 774-795. [CrossRef]

3. Tibirica, C.B.; Ribatski, G. Flow boiling in micro-scale channels-Synthesized literature review. Int. J. Refrig. 2013, 36, 301-324. [CrossRef]

4. Chexal, B.; Horowitz, J.; Lellouche, G.S. An assessment of eight void fraction models. Nucl. Eng. Des. 1991, 126, 71-88. [CrossRef]

5. Woldesemayat, M.A.; Ghajar, A.J. Comparison of void fraction correlations for different flow patterns in horizontal and upward inclined pipes. Int. J. Multiph. Flow 2007, 33, 347-370. [CrossRef]

6. Cioncolini, A.; Thome, J.R. Void fraction prediction in annular two-phase flow. Int. J. Multiph. Flow 2012, 43, 72-84. [CrossRef] 
7. Lockhart, R.W.; Martinelli, R.C. Proposed correlation of data for isothermal two-phase, two-component flow in pipes. Chem. Eng. Prog 1949, 45, 39-48.

8. Xu, Y.; Fang, X. Correlations of void fraction for two-phase refrigerant flow in pipes. Appl. Therm. Eng. 2014, 64, 242-251. [CrossRef]

9. Jin, G.; Yan, C.; Sun, L.; Xing, D.; Zhou, B. Void fraction of dispersed bubbly flow in a narrow rectangular channel under rolling conditions. Prog. Nucl. Energy 2014, 70, 256-265. [CrossRef]

10. Hashizume, K. Flow pattern, void fraction and pressure drop of refrigerant two-phase flow in a horizontal pipe-I. Experimental data. Int. J. Multiph. Flow 1983, 9, 399-410. [CrossRef]

11. Schrage, D.S.; Hsu, J.T.; Jensen, M.K. Two-phase pressure drop in vertical crossflow across a horizontal tube bundle. Aiche J. 1988, 34, 107-115. [CrossRef]

12. Xu, G.P.; Tso, C.P.; Tou, K.W. Hydrodynamics of two-phase flow in vertical up and down-flow across a horizontal tube bundle. Int. J. Multiph. Flow 1998, 24, 1317-1342. [CrossRef]

13. Wilson, M.J.; Newell, T.A.; Chato, J.C. Experimental Investigation of Void Fraction during Horizontal Flow in Larger Diameter Refrigeration Applications; ACRC Technical Report 140; College of Engineering, University of Illinois at Urbana-Champaign: Urbana, IL, USA, 1998.

14. Yashar, D.A.; Newell, T.A.; Chato, J.C. Experimental Investigation of Void Fraction during Horizontal Flow in Smaller Diameter Refrigeration Applications; ACRC Project 74; College of Engineering, University of Illinois at Urbana-Champaign: Urbana, IL, USA, 1998.

15. Koyama, S.; Lee, J.; Yonemoto, R. An investigation on void fraction of vapor-liquid two-phase flow for smooth and microfin tubes with R134a at adiabatic condition. Int. J. Multiph. Flow 2004, 30, 291-310. [CrossRef]

16. Srisomba, R.; Mahian, O.; Dalkilic, A.S.; Wongwises, S. Measurement of the void fraction of R-134a flowing through a horizontal tube. Int. Commun. Heat Mass Transf. 2014, 56, 8-14. [CrossRef]

17. Zheng, Y.; Zhang, Q. Simultaneous measurement of gas and solid holdups in multiphase systems using ultrasonic technique. Chem. Eng. Sci. 2004, 59, 3505-3514. [CrossRef]

18. Murakawa, H.; Kikura, H.; Aritomi, M. Application of ultrasonic Doppler method for bubbly flow measurement using two ultrasonic frequencies. Exp. Therm. Fluid Sci. 2005, 29, 843-850. [CrossRef]

19. Vasconcelos, A.M.; Carvalho, R.D.M.; Venturini, O.J.; França, F.A. The use of the ultrasonic technique for void fraction measurements in air-water bubbly flows. In Proceedings of the 11th Brazilian Congress of Thermal Sciences and Engineering, Curitiba, Brazil, 5-8 December 2006.

20. Jia, J.; Babatunde, A.; Wang, M. Void fraction measurement of gas-liquid two-phase flow from differential pressure. Flow Meas. Instrum. 2015, 41, 75-80. [CrossRef]

21. Revellin, R.; Dupont, V.; Ursenbacher, T.; Thome, J.R.; Zun, I. Characterization of diabatic two-phase flows in microchannels: Flow parameter results for r-134a in a $0.5 \mathrm{~mm}$ channel. Int. J. Multiph. Flow 2006, 32, 755-774. [CrossRef]

22. Sempértegui-Tapia, D.; De Oliveira Alves, J.; Ribatski, G. Two-phase flow characteristics during convective boiling of halocarbon refrigerants inside horizontal small-diameter tubes. Heat Transf. Eng. 2013, 34, 1073-1087. [CrossRef]

23. Harada, K.; Murakami, M.; Ishii, T. PIV measurements for flow pattern and void fraction in cavitating flows of He II and He I. Cryogenics 2006, 46, 648-657. [CrossRef]

24. Dowlati, R.; Kawaji, M.; Chisholm, D.; Chan, A.M. Void fraction prediction in two-phase flow across a tube bundle. AI Ch. E. J. 1992, 38, 619-622. [CrossRef]

25. Kendoush, A.A.; Sarkis, Z.A. Void fraction measurement by X-ray absorption. Exp. Therm. Fluid Sci. 2002, 25, 615-621. [CrossRef]

26. Mishima, K.; Hibiki, T. Some characteristics of air-water two-phase flow in small diameter vertical tubes. Int. J. Multiph. Flow 1996, 22, 703-712. [CrossRef]

27. Portillo, G.; Shedd, T.A.; Lehrer, K.H. Void fraction measurement in minichannels with in- situ calibration. In Proceedings of the International Refrigeration and Air Conditioning Conference; University of Wisconsin-Madison, Department of Mechanical Engineering: Madison, WI, USA, 2008.

28. Paranjape, S.; Ritchey, S.N.; Garimella, S.V. Electrical impedance-based void fraction measurement and flow regime identification in microchannel flows under adiabatic conditions. Int. J. Multiph. Flow 2012, 42, 175-183. [CrossRef] 
29. Shedd, T.A. Void Fraction and Pressure Drop Measurements for Refrigerant r410a Flows in Small Diameter Tubes; Technical Report 20110-01; University of Wisconsin: Madison, WI, USA, 2012.

30. Olivier, S.P.; Meyer, J.P.; De Paepe, M.; De Kerpel, K. The influence of inclination angle on void fraction and heat transfer during condensation inside a smooth tube. Int. J. Multiph. Flow 2016, 80, 1-14. [CrossRef]

31. De Kerpel, K.; Ameel, B.; De Schampheleire, S.; T'Joen, C.; Canière, H.; De Paepe, M. Calibration of a capacitive void fraction sensor for small diameter tubes based on capacitive signal features. Appl. Therm. Eng. 2014, 63, 77-83. [CrossRef]

32. Barreto, E.X.; Oliveira, J.L.G.; Passos, J.C. Frictional pressure drop and void fraction analysis in air-water two-phase flow in a microchannel. Int. J. Multiph. Flow 2015, 72, 1-10. [CrossRef]

33. Zhou, Y.; Chang, H.; Lv, Y. Gas-liquid two-phase flow in a horizontal channel under nonlinear oscillation: Flow regime, frictional pressure drop and void fraction. Exp. Therm. Fluid Sci. 2019, 109, 109852. [CrossRef]

34. Huang, S.; Zhang, X.; Wang, D.; Lin, Z. Equivalent water layer height (EWLH) measurement by a single-wire capacitance probe in gas-liquid flows. Int. J. Multiph. Flow 2008, 34, 809-818. [CrossRef]

35. He, D.; Chen, S.; Bai, B. Void fraction measurement of stratified gas-liquid flow based on multi-wire capacitance probe. Exp. Therm. Fluid Sci. 2019, 102, 61-73. [CrossRef]

36. Netto, J.F.; Fabre, J.; Peresson, L. Shape of long bubbles in horizontal slug flow. Int. J. Multiph. Flow 1999, 25, 1129-1160. [CrossRef]

37. Oddie, G.; Shi, H.; Durlofsky, L.J.; Aziz, K.; Pfeffer, B.; Holmes, J.A. Experimental study of two and three phase flows in large diameter inclined pipes. Int. J. Multiph. Flow 2003, 29, 527-558. [CrossRef]

38. Morris, D.; Teyssedou, A.; Lapierre, J.; Tapucu, A. Optical fiber probe to measure local void fraction profiles. Appl. Opt. 1987, 26, 4660-4664. [CrossRef] [PubMed]

39. Graindorge, P.; Le Boudec, G.; Meyet, D.; Arditty, H.J. High bandwidth two-phase flow void fraction fiber optic sensor. In Fiber Optic Sensors I. Int. Soc. Opt. Photonics 1986, 586, 211-215.

40. Spindler, K.; Bierer, M.; Lorenz, G.; Erhard, A.; Hahne, E. Measurements in vertical gas-liquid two-phase flows using an optical fiber probe. In Proceedings of the 1st World Conference on Experimental Heat Transfer, Fluid Mechanics and Thermodynamics, Dubrovnik, Croatia, 4-9 September 1988; pp. 348-357.

41. Danel, F. Local measurement in two-phase flow: Recent optical probe design developments. Houille Blanche 1978, 351-355. [CrossRef]

42. Murzyn, F.; Mouazé, D.; Chaplin, J.R. Optical fiber probe measurements of bubbly flow in hydraulic jumps. Int. J. Multiph. Flow 2005, 31, 141-154. [CrossRef]

43. Da Silva, M.J.; Schleicher, E.; Hampel, U. A novel needle probe based on high-speed complex permittivity measurements for investigation of dynamic fluid flows. IEEE Trans. Instrum. Meas. 2007, 56, 1249-1256. [CrossRef]

44. Cartellier, A.; Achard, J.L. Local phase detection probes in fluid/fluid two-phase flows. Rev. Sci. Instrum. 1991, 62, 279-303. [CrossRef]

45. Da Silva, M.J. Instrumentação em Escoamentos Multifásicos. In Proceedings of the 4th EBEM, São Paulo, Brazil; 27-31 March 2017; Escola Brasileira de Escoamento Multifásico: São Paulo, Brazil, 2017.

46. Prasser, H.M.; Böttger, A.; Zschau, J. A new electrode-mesh tomograph for gas-liquid flows. Flow Meas. Instrum. 1998, 9, 111-119. [CrossRef]

47. Da Silva, M.J.; Schleicher, E.; Hampel, U. Capacitance wire-mesh sensor for fast measurement of phase fraction distributions. Meas. Sci. Technol. 2007, 18, 2245-2251. [CrossRef]

48. Pietruske, H.; Prasser, H.M. Wire-mesh sensors for high-resolving two-phase flow studies at high pressures and temperatures. Flow Meas. Instrum. 2007, 18, 87-94. [CrossRef]

49. Manera, A.; Prasser, H.M.; Lucas, D.; Van Der Hagen, T.H.J.J. Three-dimensional flow pattern visualization and bubble size distributions in stationary and transient upward flashing flow. Int. J. Multiph. Flow 2006, 32, 996-1016. [CrossRef]

50. Peña, H.V.; Rodriguez, O.M.H. Applications of wire-mesh sensors in multiphase flows. Flow Meas. Instrum. 2015, 45, 255-273. [CrossRef]

51. Yang, W.Q.; Spink, D.M.; York, T.A.; McCann, H.J.M.S. An image-reconstruction algorithm based on Landweber's iteration method for electrical-capacitance tomography. Meas. Sci. Technol. 1999, 10, 1065. [CrossRef]

52. Yang, W.Q.; Peng, L. Image reconstruction algorithms for electrical capacitance tomography. Meas. Sci. Technol. 2002, 14, R1-R13. [CrossRef] 
53. Widyatama, A.; Dinaryanto, $\mathrm{O}$. The development of image processing technique to study the interfacial behavior of air-water slug two-phase flow in horizontal pipes. Flow Meas. Instrum. 2018, 59, 168-180. [CrossRef]

54. Wojtan, L.; Ursenbacher, T.; Thome, J.R. Interfacial measurements in stratified types of flow. Part II: Measurements for R-22 and R-410A. Int. J. Multiph. Flow 2004, 30, 125-137. [CrossRef]

55. Povolny, A.; Kikura, H.; Ihara, T. Ultrasound pulse-echo coupled with a tracking technique for simultaneous measurement of multiple bubbles. Sensors 2018, 18, 1327. [CrossRef]

56. Aritomi, M.; Zhou, S.; Takeda, Y.; Nakamura, H.; Kukita, Y. Measurement of Bubbly Flows in Vertical Channels Using Ultrasonic Velocity Profile Monitor; International Atomic Energy Agency (IAEA): Vienna, Austria, 1998.

57. Wallis, G.B. Use of the Reynolds Flux Concept for Analysing One-Dimensional Two-Phase Flow. Int. J. Heat Mass Transf. 1969, 11, 445-458. [CrossRef]

58. Tang, C.; Heindel, T.J. Similitude analysis for gas-liquid-fiber flows in co-current bubble columns. In Proceedings of the Fluids Engineering Division Summer Meeting, Miami, FL, USA, 17-20 July 2006; Volume 47500, pp. 1787-1798.

59. Keinath, B.L. Void Fraction, Pressure Drop, and Heat Transfer in High Pressure Condensing Flows through Microchannels. Ph.D. Thesis, Georgia Institute of Technology, Atlanta, GA, USA, 2012.

60. Kandlikar, S.G. Fundamental issues related to flow boiling in minichannels and microchannels. Exp. Therm. Fluid Sci. 2002, 26, 389-407. [CrossRef]

61. Lips, S.; Meyer, J.P. Experimental study of convective condensation in an inclined smooth tube. Part I: Inclination effect on flow pattern and heat transfer coefficient. Int. J. Heat Mass Transf. 2012, 55, 395-404. [CrossRef]

62. Milkie, J.A.; Garimella, S.; Macdonald, M.P. Flow regimes and void fractions during condensation of hydrocarbons in horizontal smooth tubes. Int. J. Heat Mass Transf. 2016, 92, 252-267. [CrossRef]

63. Wojtan, L. Experimental and Analytical Investigation of Void Fraction and Heat Transfer during Evaporation in Horizontal Tubes. Ph.D. Thesis, Ecole Polytechnique Federale de Lausanne (EPFL), Lausanne, Switzerland, 2004.

64. Canière, H. Flow Pattern Mapping of Horizontal Evaporating Refrigerant Flow Based on Capacitive Void Fraction Measurements. Ph.D. Thesis, Ghent University, Ghent, Belgium, 2009.

65. Graham, D.M. Experimental Investigation of Void Fraction during Refrigerant Condensation; Technical Report ACRC Project 74; College of Engineering, University of Illinois at Urbana-Champaign: Urbana, IL, USA, 1997.

66. Kopke, H.R. Experimental Investigation of Void Fraction during Refrigerant Condensation in Horizontal Tubes; Air Conditioning and Refrigeration Center, College of Engineering, University of Illinois at Urbana-Champaign: Urbana, IL, USA, 1998.

67. Hughmark, G.A. Holdup and heat transfer in horizontal slug gas-liquid flow. Chem. Eng. Sci. 1965, 20, 1007-1010. [CrossRef]

68. Rouhani, S.Z.; Axelsson, E. Calculation of void volume fraction in the subcooled and quality boiling regions. Int. J. Heat Mass Transf. 1970, 13, 383-393. [CrossRef]

69. Zuber, N.; Findlay, J. Average volumetric concentration in two-phase flow systems. J. Heat Transf. 1965, 87, 453-468. [CrossRef]

70. Dix, G.E. Vapor Void Fractions for Forced Convection with Subcooled Boiling at Low Flow Rates. Ph.D. Thesis, University of California, Berkeley, CA, USA, 1971.

71. Chisholm, D. Pressure gradients due to friction during the flow of evaporating two-phase mixtures in smooth tubes and channels. Int. J. Heat Mass Transf. 1973, 16, 347-358. [CrossRef]

72. Domanski, P.A.; Didion, D. Computer Modeling of the Vapor Compression Cycle with Constant Flow Area Expansion Device; National Institute of Standards and Technology (NIST): Washington, DC, USA, 1983.

73. Spedding, P.L.; Chen, J.J.J. Holdup in two phase flow. Int. J. Multiph. Flow 1984, 10, 307-339. [CrossRef]

74. Kariyasaki, A.; Fukano, T.; Kagawa, M. Characteristics of Time Varying Void Fraction in Isothermal Air-Water Concurrent Flow in a Horizontal Capillary Tube. In Proceedings of the 1991 ASME JSME Thermal Engineering Joint Conference, Reno, NV, USA, 17-22 March 1991.

75. Graham, D.M.; Kopke, H.R.; Wilson, M.J.; Yashar, D.A.; Chato, J.C.; Newell, T.A. An Investigation of Void Fraction in the Stratified/Annular Flow Regions in Smooth, Horizontal Tubes; Air Conditioning and Refrigeration Center, College of Engineering, University of Illinois at Urbana-Champaign: Urbana, IL, USA, 1999. 
76. Niño, V.G.; Hrnjak, P.S.; Newell, T.A. Characterization of Two-Phase Flow in Microchannels; Air Conditioning and Refrigeration Center, College of Engineering, University of Illinois at Urbana-Champaign: Urbana, IL, USA, 2002.

77. Kawahara, A.; Sadatomi, M.; Okayama, K.; Kawaji, M.; Chung, P.Y. Effects of channel diameter and liquid properties on void fraction in adiabatic two-phase flow through microchannels. Heat Transf. Eng. 2005, 26, 13-19. [CrossRef]

78. Zhang, W.; Hibiki, T.; Mishima, K. Correlations of two-phase frictional pressure drop and void fraction in mini-channel. Int. J. Heat Mass Transf. 2010, 53, 453-465. [CrossRef]

79. Kanizawa, F.T.; Ribatski, G. Void fraction predictive method based on the minimum kinetic energy. J. Braz. Soc. Mech. Sci. Eng. 2016, 38, 209-225. [CrossRef]

80. Karayiannis, T.G.; Mahmoud, M.M. Flow boiling in microchannels: Fundamentals and applications. Appl. Therm. Eng. 2017, 115, 1372-1397. [CrossRef]

Publisher's Note: MDPI stays neutral with regard to jurisdictional claims in published maps and institutional affiliations.

(C) 2020 by the authors. Licensee MDPI, Basel, Switzerland. This article is an open access article distributed under the terms and conditions of the Creative Commons Attribution (CC BY) license (http://creativecommons.org/licenses/by/4.0/). 